\title{
Review
}

\section{Four central questions about prediction in language processing}

\author{
Falk Huettig ${ }^{a, b, *}$ \\ ${ }^{a}$ Max Planck Institute for Psycholinguistics, P.O. Box 310, 6500 AH Nijmegen, The Netherlands \\ ${ }^{\mathrm{b}}$ Donders Institute for Brain, Cognition, and Behaviour, Radboud University, Nijmegen, The Netherlands
}

\section{A R T I C L E I N F O}

Article history:

Accepted 7 February 2015

Available online 20 February 2015

Keywords:

Language processing

Prediction

\begin{abstract}
A B S T R A C T
The notion that prediction is a fundamental principle of human information processing has been en vogue over recent years. The investigation of language processing may be particularly illuminating for testing this claim. Linguists traditionally have argued prediction plays only a minor role during language understanding because of the vast possibilities available to the language user as each word is encountered. In the present review I consider four central questions of anticipatory language processing: Why (i.e. what is the function of prediction in language processing)? What (i.e. what are the cues used to predict up-coming linguistic information and what type of representations are predicted)? How (what mechanisms are involved in predictive language processing and what is the role of possible mediating factors such as working memory)? When (i.e. do individuals always predict up-coming input during language processing)? I propose that prediction occurs via a set of diverse PACS (production-, association-, combinatorial-, and simulation-based prediction) mechanisms which are minimally required for a comprehensive account of predictive language processing. Models of anticipatory language processing must be revised to take multiple mechanisms, mediating factors, and situational context into account. Finally, I conjecture that the evidence considered here is consistent with the notion that prediction is an important aspect but not a fundamental principle of language processing.

This article is part of a Special Issue entitled SI: Prediction and Attention.
\end{abstract}

c 2015 Elsevier B.V. All rights reserved.

\section{Contents}

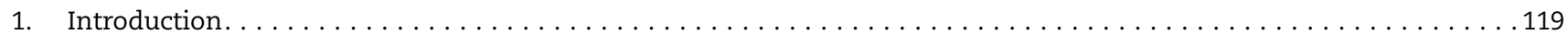

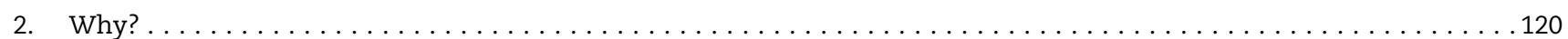

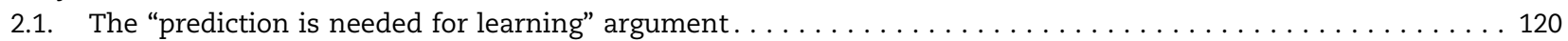

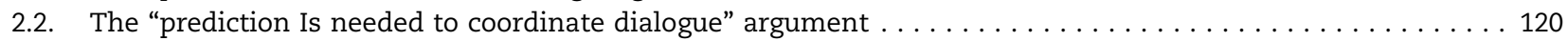

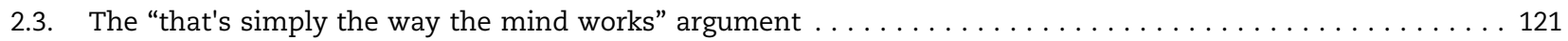

*Correspondence address: Max Planck Institute for Psycholinguistics, P.O. Box 310, 6500 AH Nijmegen, The Netherlands.

E-mail address: falk.huettig@mpi.nl 


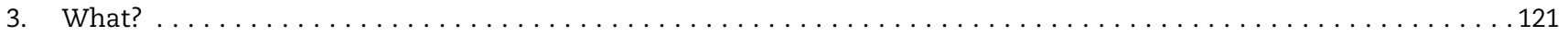

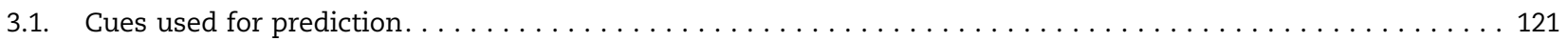

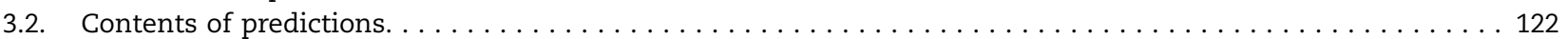

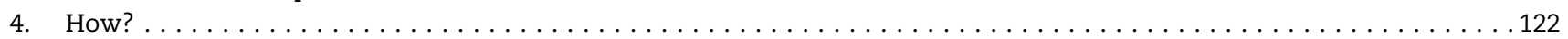

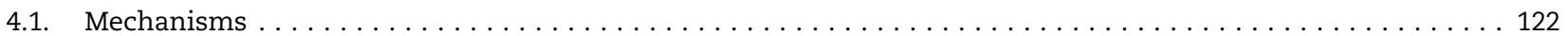

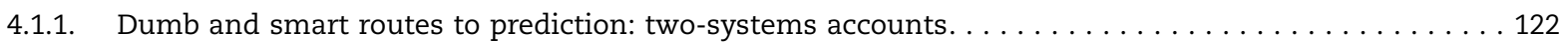

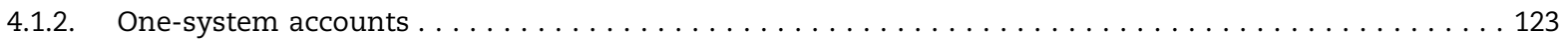

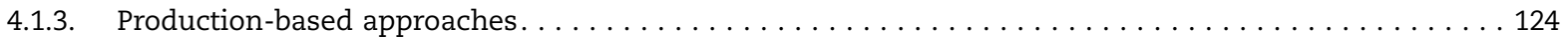

4.1.4. PACS (production-, association-, combinatorial-, simulation-based prediction) - a multiple-mechanisms

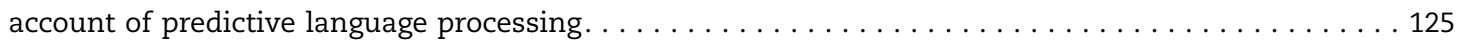

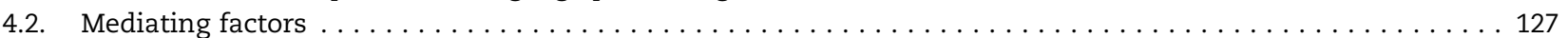

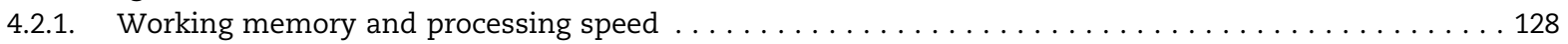

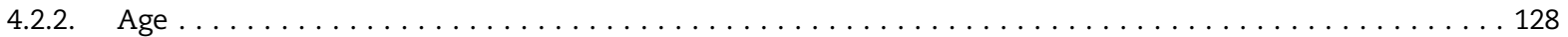

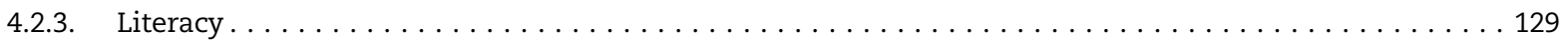

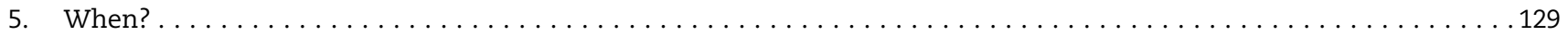

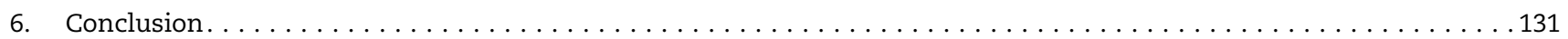

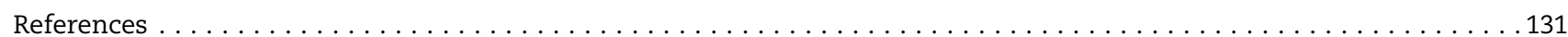

\section{Introduction}

The notion that prediction is a fundamental aspect of human information processing is not new and can be traced back as far as the writings of von Helmholtz (1860/1962) and James (1890). Over recent years however there has been a surge in the experimental study of prediction particularly in the fields devoted to the investigation of the relationship between perception and action. Many studies suggest that people predict the outcome of the actions of others as they unfold (Sebanz and Knoblich, 2009). Ensemble musicians for instance generate online predictions by simulating the concurrent productions of their co-musicians (Keller and Koch, 2008; Wolpert et al., 2003). Knowing the task of a co-actor appears to influence one's own planning and performance even in situations that do not require taking the other's task into account (Sebanz et al., 2003, 2005). Mere knowledge of another person's upcoming hand movements activates our own motor systems even when no actual movement is seen (Kilner et al., 2004). Motor activation has also been observed when individuals use visual cues to prepare their own actions as well as when they use the same cues to predict someone else's actions (Ramnani and Miall, 2004). Similar results have been reported in developmental studies. Infants' motor development relies strongly on perception and knowledge of up-coming events (Von Hofsten, 2004; see also Hunnius and Bekkering (2010)). Anticipatory eye movements have been reported in a great variety of real world tasks including tea-making (Land et al., 1999), sandwich-making (Hayhoe et al., 2003), driving (Land and Lee, 1994), and piano-playing (Land and Furneaux, 1997). This kind of predictive eye gaze is thought to support visuomotor coordination (Mennie et al., 2007).

Experimental evidence such as this has led to the development of increasingly optimistic theoretical accounts of predictive processing. Clark (2013), see also Friston (2010) for instance suggests that prediction "offers a distinctive account of neural representation, neural computation, and the representation relation itself" and a "deeply unified account of perception, cognition, and action". Clark even goes so far as to claim that "brains ... are essentially prediction machines". The study of human language processing offers great opportunities to test such claims. This is because linguists traditionally have been quite pessimistic about prediction being a fundamental influence on language processing. Prediction, many linguists argue, plays only a minor role during language understanding because of the vast possibilities available to the language user as each word is encountered. Jackendoff (2007), for example, has argued "predicting the next word has no bearing whatsoever on an explanation of speech production, where the goal has to be to produce the next word in an effort to say something meaningful". "What good would such predictions do in understanding the sentences?" Jackendoff asks. Indeed, if prediction is a central characteristic of human cognition it should also be a central characteristic of human language processing.

Results of many psycholinguistic experiments however suggest that one reason why language processing tends to be so effortless, accurate, and efficient may be that mature (e.g., DeLong et al., 2005; Federmeier and Kutas, 1999; Van Berkum et al., 2005; Wicha et al., 2004) and developing (e.g., Borovsky et al., 2012; Nation et al., 2003; Mani and Huettig, 2012) language users predict upcoming language input. Many psycholinguists therefore have proposed an important role for anticipatory language processing. Federmeier and Kutas (1999) conclude from their electrophysiological research "in the course of processing a sentence, the comprehension system is involved in some process tantamount to prediction". Pickering and Garrod (2013) ascribe "a central role to prediction in language production, comprehension, and dialogue". Chang et al. (2006) argue that "learning occurs because prediction occurs" and that therefore "syntactic abstractions arise from learners making tacit predictions". Finally, Altmann and Mirković (2009) conclude that "prediction across time is key to the emergence of event structure" and that "most likely, therefore, prediction has a neural basis that pervades cortical function". To evaluate such claims I believe it is useful to pose and answer four central questions about predictive language processing. Why (i.e. what is the function of prediction in language processing)? What (i.e. what are the cues used to predict up-coming linguistic information and what type of representations are predicted)? How (what mechanisms are involved in predictive language processing and what is the role of possible mediating factors such as working 
memory)? When (i.e. do individuals always predict up-coming input during language processing)?

\section{Why?}

There are many obvious potential benefits of prediction in language processing. Prediction may allow for faster processing and increased efficiency of mental operations. It can reduce much of the ambiguity inherent in most linguistic utterances and thus reduce memory load. There are however some more fundamental arguments about the function of prediction in language processing.

\subsection{The "prediction is needed for learning" argument}

Since the cognitive revolution in the 1950s linguists have stressed the fact that one of the most remarkable characteristics of human language is that language users can understand and produce an infinitely large number of phrases and sentences they have never experienced before. Linguists have argued that language users cannot store all possible utterances in their brains; they have to construct utterances on the fly using structural principles. Jackendoff (2002) for instance is therefore pessimistic that experience-based approaches (such as connectionist networks, e.g. Elman, 1990) can provide a sufficient account of the characteristic combinatoriality of language processing. Connectionist modellers (e.g., Elman, 1990) have shown that simple recurrent networks can learn to make predictions by using the conditional probabilities of succeeding chunks. This is because information about distributional constraints on the context in which particular chunks occur is picked up by recurrent networks to learn representations which correspond to syntactic and semantic categories. A key success of recurrent networks is that they seem to be able to encode long-distance dependencies such as the dependencies that occur in whquestions and relative clauses (but see Jackendoff (2002, p. 62), for arguments that sequential dependencies among words are insufficient to determine grammaticality). Importantly, these networks are able to generalize to novel instances. Learning then occurs as a consequence of simple recurrent networks' ability to detect predictive dependencies. Saffran argues that predictive dependencies (such that the or $a$ is usually followed by a noun) allow language learners to acquire abstract structure. She argues that dependencies in linguistic phrase structure are detected by language learners and used to establish sequences of words that cluster into phrases. This learning process is thought to modulate successive analyses leading to an accentuation of syntactic relations within and dependencies between phrases. Some considerable experimental support for statistical learning has been obtained. Saffran et al. (1996), for example, presented 8month-olds with a continuous spoken sequence of multisyllabic words from a nonsense language (e.g. golabupabikututibubabupugolabubabupu...). The only cues which could be used to segment the words and detect word boundaries without obvious acoustic cues were the statistical dependencies between the syllables in the sequence. Saffran et al. found that the 8-month-olds discriminated sequences such as golabu and pabiku from sequences which crossed word boundaries such as bupabi (see Romberg and Saffran (2010), for a review). These kinds of results could be and indeed have been interpreted as indexing individuals' prediction of upcoming syllables. In other words, the ability to extract statistical regularities is thought to be linked to an individual's prediction skills (cf. Conway et al., 2010; Misyak et al., 2010). Indeed, many psycholinguists (e.g., Chang et al., 2006; see also Rowland et al. (2012) and Chang et al. (2013)) argue that prediction is needed for language learning to take place.

Note however that the ability to extract forward statistical regularities does not necessarily tell us about the extent to which such results are driven by prediction. Importantly, language learning does not necessarily have to involve prediction. It has been shown that infants (Pelucchi et al., 2009) and adults (Perruchet and Desaulty, 2008) also track backward transitional probabilities. Importantly, such backward statistics are often more informative then forward transitional probabilities (see also St Clair et al. (2009)). For instance, backward transitional probabilities are more informative than forward statistics to learn which of the articles in German (i.e. der, die, or das) precedes a noun since the articles itself are only poor predictors of a specific noun. This is not an isolated example. Corpus analyses in English suggest that backward transitional probabilities are more informative than forward statistics for learning the grammatical category "noun" (Willits et al., 2009). These findings suggest that "postdiction" is just as (or even more) important than prediction and raises serious doubts about claims that prediction is absolutely necessary for language learning (as well as language processing more generally). I will return to this issue in Section 6 (Conclusions).

\subsection{The "prediction Is needed to coordinate dialogue" argument}

Another key function of anticipatory language processing may be to facilitate mutual understanding or to coordinate dialogue as a joint activity (cf. Clark, 1996). Pickering and Garrod (2007) point out that in dialogue often a question, for example, requires one of a small range of answers (e.g., "Are you going to behave better in future?"). They argue that dialogue facilitates the alignment of interlocutors' mental states (see also Pickering and Garrod (2004)) and explains the tight coupling of interlocutors. They follow Prinz (2006) in proposing that prediction facilitates overt imitation. Prediction and imitation, Pickering and Garrod (2007) argue, explains why conversation typically is so effortless even though it involves constant task-switching and requires the planning of when to speak and what to say. Evidence for this comes from observations that people often complete other's utterances (e.g., Clark and Wilkes-Gibbs, 1986). De Ruiter et al. (2006) presented evidence that listeners are highly accurate in predicting the end of other speakers' turns; McFarland (2001) that speakers coordinate their breathing; and Pardo (2006) that conversation partners' pronunciations converge. Wilson and Wilson (2005) moreover argue that conversation partners synchronize their syllabic speech rates during dialogue. Finally, Scott et al. (2009) propose that during dialogue the temporal lobes and associated regions of the brain track the meaning of what is being said, and the motor system at the same time tracks speech rate and rhythm of the talker to ensure efficient turn-taking. An argument against the notion that prediction is needed to coordinate dialogue is that much of the above evidence has been obtained in very restricted 
contexts in which it may have been very easy to (for instance) complete conversation partners' utterances. I will return to this point in Section 5 (When?) when discussing the influence of "prediction encouraging experimental set-ups" which have frequently been used.

\subsection{The "that's simply the way the mind works" argument}

Clark (2013) argues that the greatest value of the actionoriented predictive processing framework lies in that it has put forward a set of deep unifying principles for our understanding of the human mind in terms of neural function and organization. Similarly, Friston (2010) claims that the brain is fundamentally engaged in predictive coding and computes precise prediction errors which bias towards making correct inferences. He argues that predictive coding leads to a minimization of prediction error though recurrent or reciprocal interactions among levels of a cortical hierarchy. If these ideas are correct we should find evidence for this in human language processing since language is an important part of the information our minds process. Thus, in order to evaluate the "why question" of predictive language processing it is necessary to consider the "what", "how", and "when questions" to which I will now turn.

\section{What?}

There are two important questions to be asked concerning the "what question". The first concerns the cues used for prediction: What types of information are used to anticipate upcoming words? The second concerns the contents of prediction: What types of representations are activated?

\subsection{Cues used for prediction}

An important aspect of speech that listeners could use for prediction is the regularities present in connected speech (Rothermich and Kotz, 2013). Brady (1971) for example showed that stutterers speak more fluently with the help of a metronome. Timing cues also appear to help patients with Parkinson's disease (Kotz et al., 2009; McIntosh et al., 1997). Again, it is important to note here however that findings that individuals are able to use timing cues for language production tell us little about the extent to which they actually use these regularities for prediction. More direct evidence about the cues used for prediction in language processing has accumulated using different types of methods, most importantly eye-tracking during reading, electrophysiological studies, and visual world eye-tracking. I will consider the relevant findings from these methods in turn.

Reading studies have shown that predictable words are read faster than unpredictable words (Ehrlich and Rayner, 1981; Rayner and Well, 1996). Staub and Clifton (2006) observed that readers predict an "or" clause if they have previously read an "either" clause. McDonald and Shillcock (2003), in two reading eye-tracking studies, presented evidence that transitional probabilities between words predict fixation durations. They took these findings to argue that transitional probabilities and word co-occurrence statistics are used by readers to predict up-coming words. They also presented a Bayesian statistical model, which suggests that lexical probabilities (derived by combining transitional probability with the prior probability of a word's occurrence) provide a good explanation of fixation behaviour. Frisson et al. (2005) however have questioned whether effects of low level transitional probabilities are independent from what they call "regular" (i.e. higher level) predictability effects typically determined by the use of a Cloze task in which participants are asked to complete sentences or sentence fragments. Predictability in this task is determined by calculating the percentage of times a particular word is given for a particular sentence. Frisson and colleagues replicated the findings of McDonald and Shillcock (2003) in a first experiment but in their second experiment when items were matched for Cloze values no effect of transitional probabilities was found. This finding therefore casts doubt on the explanation that readers track transitional probabilities to predict upcoming words during reading.

Most electrophysiological studies on the cues of prediction have interpreted differences in the ERP N400, a negative component that peaks at around $400 \mathrm{~ms}$ after the onset of a meaningful stimulus. The $\mathrm{N} 400$ has been shown to be a sensitive index of semantic processing (Kutas and Hillyard, 1984, for recent review see Kutas and Federmeier (2011)). Federmeier and Kutas (1999) showed participants written sentences (presented word-byword) such as "They wanted to make the hotel look more like a tropical resort. So along the driveway, they planted rows of...". These sentences were followed either by a predictable word (e.g., "palms"), or an unexpected word from the same semantic category (e.g., "pines"), or an unexpected word from a different category (e.g., "tulips"). Federmeier and Kutas found that N400 amplitude to the unexpected words was attenuated when the word was related to the expected word (e.g., "pines") relative to when it was unrelated (e.g., "tulips"). This suggests that semantic category information had been pre-activated (i.e. predicted) based on the sentential context.

Most studies investigating predictive language processing have presented isolated sentences to participants. Van Berkum et al. (2005) looked at the role of wider discourse on the prediction of upcoming words in Dutch (e.g., passages such as, translated into English, "The burglar had no trouble locating the secret family safe. Of course, it was situated behind a..."). ERPs to determiners and adjectives were measured for predictionconsistent (e.g., "bigNEU paintingNEU", NEU refers to Dutch neuter gender) and prediction-inconsistent words (e.g., "bigCOM bookcaseCOM", COM refers to Dutch common gender). Van Berkum et al. found an enhanced N400 effect for adjectives inconsistent with the discourse predictable noun relative to adjectives consistent with the discourse-predictable noun. These findings therefore suggest that people also use wider discourse context to predict upcoming linguistic information. Converging evidence for the use of sentential and discourse context comes from visual world eye-tracking studies in which listeners show anticipatory eye movements to visual objects making use of constraints in the visual world and unfolding auditory linguistic information (e.g., Altmann and Kamide, 1999; Kamide et al., 2003; Kaiser and Trueswell, 2004; see Huettig et al. (2011), for a recent review of the paradigm). These types of eye-tracking studies have shown that listeners can use many types of specific cues for prediction including case-marking (Kamide et al., 2003), 
prosody (Weber et al., 2006), and visually presented events (Knoeferle et al., 2005).

\subsection{Contents of predictions}

Electrophysiological studies have also provided some evidence about what types of representations are activated during predictive language processing. These studies showed that language users can pre-activate the semantic/conceptual features (Federmeier and Kutas, 1999; Federmeier et al., 2002), morphosyntactic features (Van Berkum et al., 2005; Wicha et al., 2003b; Wicha et al., 2004), the phonological form (DeLong et al., 2005), and the orthographic form (Laszlo and Federmeier, 2009) of a predicted concept.

Visual world eye-tracking studies have also shown that the contents of language users' predictions include semantic information (e.g., Altmann and Kamide, 1999; Mani and Huettig, 2012; cf. Huettig \& Altmann, 2005). An important question is how far such pre-activation cascades in the cognitive system. It is perhaps not surprising that semantic information can be predicted; after all it is making sense of the meaning of an utterance which is crucial for language comprehension. If prediction is a fundamental principal of language processing and cognition more generally however one would expect that "less crucial" types of information are also predicted. Rommers et al. (2013) investigated whether listeners also activate specific visual information such as the shape of the words' referents. In a visual world eye tracking experiment listeners' eye movements were tracked while they were listening to sentences that were strongly predictive of a specific target word (e.g., "moon" in "In 1969 Neil Armstrong was the first man to set foot on the moon"). Half a second before the acoustic onset of the target word, participants were presented with fourobject displays showing three unrelated distractor objects and a critical object (either the target object, e.g., moon, an object with a similar shape, e.g., tomato, or an unrelated control object, e.g., rice). Participants fixated both the target and the shape competitors more often than the unrelated distractor objects before the critical noun (e.g. "moon") was heard, which suggests that they had predicted the shape of the upcoming word's referent. Converging evidence was obtained in a second experiment, an ERP experiment, without picture displays. Participants listened to the same lead-in sentences as in the first experiment but sentencefinal words corresponded to the predictable target, the shape competitor, or the unrelated control object (e.g., "In 1969 Neil Armstrong was the first man to set foot on the moon/tomato/rice"). Roomers et al. observed a significantly attenuated N400 amplitude in response to the final words in the shape-related compared to the unrelated condition. Listeners therefore appear to activate perceptual attributes of objects before they are referred to in an utterance. More generally, these data (i.e. pre-activation of predicted concepts cascades to stored visual-form levels) could be interpreted to fit with the notion that prediction is a fundamental principle of language processing (Clark, 2013). It is important to note however that the shape prediction effect in the Rommers et al. study was quite small relative to the target prediction effect. Further research exploring the extent of pre-activation of different types of mental representations during language processing is required.

\section{How?}

Most research on predictive language processing in the last 15-20 years has focused on demonstrating that prediction is an important part of language processing. Much less research has been directed at establishing the mechanisms and mediating factors of anticipatory language processing. Over recent years researchers however have started to investigate this crucial topic more directly.

In order to evaluate the merits of the different mechanisms of prediction which have been proposed in the literature it is important to precisely define what is meant by prediction. I consider prediction in language processing to be the: pre-activation/retrieval of linguistic input before it is encountered by the language comprehender. An important (but controversial) question is whether priming should be seen as a part of prediction. There are plenty of demonstrations in the literature that word recognition is facilitated by the prior occurrence of related (e.g. phonological, orthographic, semantic, visual) information (i.e. priming, see below). There is also strong evidence for the pre-activation of these representations in the absence of priming (often termed "active forecasting" or "prediction using event knowledge", see below). I conjecture that excluding priming (sometimes termed "expectation") when discussing prediction is not very useful. I believe that one cannot (or at least should not) avoid considering the influence of priming when discussing the mechanisms of the pre-activation/retrieval of linguistic input. In the following section it will become immediately clear why.

\subsection{Mechanisms}

\subsubsection{Dumb and smart routes to prediction: two-systems} accounts

The notion that the human mind makes use of two (at least partly) distinct systems has gained much support over recent years. Kahneman (2011) (cf. Stanovich and West, 2000) describes system 1 as operating "automatically and quickly, with little or no effort and no sense of voluntary control". System 2 on the other hand is assumed to "allocate attention to the effortful mental activities that demand it, including complex computations. The operations of system 2 are often associated with the subjective experience of agency, choice, and concentration". Kahneman's system 2 is similar to what Duncan (2010) calls the multiple-demand system involving the frontal lobes (thought to be accompanied by a sense of active control and individual attention).

I suggest that Kahneman's systems 1 and 2 can be linked to different routes of predictive language processing. System 1 is the "dumb" route to prediction: simple associative mechanisms (e.g. based on Hebbian learning) lead to pre-activation of linguistic input (cf. Bar, 2007, 2009). System 2 is the "smart" route to prediction and linked to more effortful active reasoning. The more general idea of linking predictive language processing to two partly distinct routes is by no means new. Kuperberg (2007) has linked the N400 and P600 event-related potentials to two competing neural processing streams. The first stream (which Kuperberg calls "semantic-memory based") is similar to Kahneman's system 1. According to Kuperberg the task of this stream is to compute "semantic features, associative relationships and 
other types of semantic relationships between content words (including verbs and arguments) within a sentence, and to compare these relationships with those that are pre-stored within lexical semantic memory". She suggests that the N400 ERP component is partly sensitive to these types of computations. Kuperberg terms the second processing stream (which has similarities with what Kahneman calls system 2) "combinatorial". She argues that the stream involves "the combination of words through algorithmic mechanisms to build up higher-order meaning" and that the P600 ERP component reflects a continued analysis within this combinatorial system.

Semantic priming studies suggest that temporal and inferior prefrontal regions are sensitive to associative relationships (e.g. Copland et al., 2003; Kotz et al., 2002; Matsumoto et al., 2005; Rossell et al., 2003). The same brain regions (in fMRI studies) appear to be activated for the semantic incongruities that evoke the N400 in ERP studies (Hagoort et al., 2004; Kiehl et al., 2002; Kuperberg et al., 2003). Moreover, Halgren et al. (2002) report MEG evidence that activation of these regions is time-locked to the onsets of semantically anomalous words. These results are therefore consistent with the notion that language comprehension involves a "constant comparison between semantic associative relationships between incoming words and information stored within semantic memory" (Kuperberg, 2007).

System 2 in contrast is thought to involve posterior inferior frontal cortices, motor and parietal cortices, and middle and superior prefrontal cortices (Friederici et al., 2003; Kuperberg, 2007; Kuperberg et al., 2003; Ni et al., 2000). These regions appear to be activated by both morphosyntactic violations and semantic-thematic violations (and evoke P600s) consistent with the idea that system 2 is a "combinatorial stream", sensitive to multiple linguistic constraints and the building up of higherorder meaning.

It is important to note that many of the functional roles of the components of both (neural) systems are yet unknown and most proposals are very speculative. Evidence for the neural mechanisms for system 1 (e.g. based on Hebbian learning) appears more straightforward than for the more complex system 2. It has been argued for instance that the activation of posterior frontal, motor, and parietal cortices in system 2 may reflect a mirror neuron system linking motor action to syntactic processing (e.g. Arbib, 2005). There is however currently little concrete evidence to support such claims. It is also important to note that although systems 1 and 2 are partly distinct they are thought to constantly interact. Kuperberg (2007) for instance argues that the balance between the two systems is dynamic and influenced by task demands, context, and individual differences such as working memory. I will return to this issue below when discussing the mediating factors of predictive language processing.

Further progress in understanding the mechanisms underlying predictive language processing will require converging evidence from different experimental methods. Kukona et al. (2011) directly contrasted the effect of local priming with the effect of event-based sentence context on the prediction of upcoming input in a visual world eye-tracking study. Participants heard active subject-verb-object sentences which included verbs such as arrest (e.g., Toby arrests the crook) while they were looking at visual scenes which included verb-related agents (e.g., a policeman) and patients (e.g. a crook). Participants exhibited anticipatory eye gaze to both agents (the policeman) and patients (the crook) although the agent role had already been filled (Toby). Thus, simple associations (arrest-policeman) and combinatorial event information influenced anticipatory eye gaze although the associations conflicted with the event built up by the sentential context as predicted by two-system accounts.

\subsubsection{One-system accounts}

Altmann and Mirković (2009) in contrast argue that the "sharing of a representational substrate between language processing and event encoding gives rise to an equivalence between linguistic representations and corresponding non-linguistic representations that drives not only language-mediation of visual attention but also the mapping of language onto event structures". In other words, Altmann and Mirkovic assume not only that linguistic prediction is based on a single system but also that there is no distinction between linguistic and non-linguistic prediction. They argue that simple recurrent (connectionist) networks (Elman, 1990) with shared hidden units can learn linguistic and non-linguistic contingencies resulting in prediction without any explicit linguistic level of representation. One-system accounts of prediction are similar to common coding approaches in perception and action (e.g., Prinz, 1990) and contrast (for instance) with accounts in which independent representations of utterance meaning, scene information, and linguistic expectations are related through processes of coindexation (e.g. Knoeferle and Crocker, 2007).

What evidence is there to support the notion of a single system of prediction? One way to provide support for common coding approaches to prediction is to look at individual differences. A positive correlation of individuals' tendency to predict in linguistic prediction and non-linguistic prediction tasks would at least be consistent with a shared system. Rommers et al. (in press) looked at whether mechanisms of predictive language processing involve specific verbal factors or processes shared with other domains of cognition. The same stimuli as in Rommers et al. (2013) were used, i.e. participants listened to sentences ending in a highly predictable word while viewing displays containing three unrelated distractor objects and a critical object, which was either the target object, or an object with a similar shape, or an unrelated control object. They found that fixation probabilities to shape competitors were systematically related to individual differences in anticipatory attention, as indexed by a spatial cueing task (cf. Posner, 1980). The participants whose responses were most strongly facilitated by predictive arrow cues also were the ones who showed the strongest anticipatory eye movements in the language task. In contrast, fixation probabilities to the targets were related to individual differences in vocabulary size and verbal fluency. Overall anticipatory eye movements to targets and shape competitors differed in magnitude and timing as well as the pattern of individual differences which correlated with target and shape competitor prediction. These results are indicative that verbal and nonverbal factors contribute to different types of mechanisms of predictive processing. These findings, arguably, are therefore more consistent with two systems or multiple systems than with one system accounts of prediction in language processing though further research is required to look at this issue more closely.

One system accounts typically ascribe an important role to event knowledge in predictive language processing (e.g., 
Metusalem et al., 2012). Events tend to reoccur and show regularities and therefore are likely to be an important organizing principle of past experience. Metusalem et al. (2012) investigated whether event knowledge is immediately accessible during online language processing and a major determinant of predictive language processing. Their participants read sentence passages describing typical events such as: A huge blizzard ripped through town last night. My kids ended up getting the day off from school. They spent the whole day outside building a big snowman/jacket/ towel in the front yard. Metusalem et al. found that contextually anomalous words related to the described event (e.g. jacket) elicited a reduced N400 amplitude compared to equally anomalous words which were unrelated to the described event (e.g., towel). Further experiments and analyses of the data suggested that the effect was not due to simple priming or word associations (for instance between blizzard and jacket). The authors concluded that event knowledge drives predictive language processing.

Note that Kukona et al. (2011) discuss how their results (i.e. evidence for prediction based on priming and "active forecasting") could be accounted for in a single system. The argument is that activation of a representation in a recurrent network can be conceptualized as distance from the current state in multidimensional space. Priming could be based on proximity to trajectories in past experience (i.e. the prime may "pull" the system to a region associated with a probe). Active forecasting on the other hand, they argue, may result from the system following a certain trajectory. This interpretation makes clear how difficult it is to distinguish between two- and one-system accounts. One-system accounts/common coding approaches are (arguably) elegant but a problematic issue is that they are very difficult to falsify (cf. Popper, 1959).

\subsubsection{Production-based approaches}

A third type of potential mechanism of prediction which has been influential over recent years assumes that we use the language production system covertly to anticipate language input (e.g., Chang et al., 2006; Dell and Chang, 2014; Pickering and Garrod, 2007, 2013; Schiller et al., 2009). Some of these accounts also involve dual pathways or systems. I discuss these models in this section however because proponents of these accounts tend to regard the "production route" as the crucial one (or at least discuss the "production route" much more extensively).

Chang and colleagues developed a dual path model consisting of a meaning system and a sequencing system. These two systems converge on a word output layer to ensure the right timing of the production of words consistent with the intended message. The meaning system is assumed to be involved in the binding of concepts and event roles. The sequencing system is an error-based learning mechanism. Importantly, the syntactic abstractions required for the production of sentences arise from learners' predictions about upcoming words. Learning therefore occurs when the model's production-based predictions are compared against productions generated by others. Similar to predictive coding accounts in perception and action, prediction error is assumed to result in adjustments to the system which generated the predictions.

Pickering and Garrod (2013) also ascribe a major role to production-based processes in predictive language processing. Pickering and Garrod argue that language users use forward production models in a similar way that actors use forward action models (cf. Wolpert et al., 2003). Speakers are assumed to construct efference copies of their predicted productions and compare these copies with the output of a production implementer. They suggest that listeners also use these forward production models and covertly imitate speakers to predict the speaker's upcoming utterances. Importantly, these "predictions-by-simulation" are assumed to be impoverished representations rather than fully implemented production representations. Pickering and Garrod (2013) argue that their prediction-by simulation route is complemented by an association route which is based on the probability of a word being uttered in the language users' experience of others' utterances. McCauley and Christiansen (2011) on the other hand view language production and comprehension as a single system based on a single set of statistical information and representations. Syntactic knowledge is thought to accumulate through abstraction over multi-word sequences. Words are chunked together based on transitional probabilities as incoming utterances are processed. McCauley and Christiansen argue that the distributional information of the chunks employed during production is used to predict upcoming language input during comprehension.

What evidence supports production-based accounts? Several studies have shown that articulatory muscles are active when listening to speech but not non-speech sounds (Fadiga et al., 2002, Watkins et al., 2003; and Scott et al., 2009, for review). Note however that evidence for activation of the motor cortex in speech perception is not evidence that the motor system is necessarily involved in generating predictions.

Kara Federmeier and colleagues have also linked predictive language processing to language production. Their novel approach is to make this link based on evidence of hemispheric differences. It has long been known that damage to left hemisphere brain areas can cause severe deficits in many language functions whereas damage to the analogous right hemisphere areas appears to leave much of language processing intact (see Hellige (1993), for a comprehensive discussion of neural asymmetries). Federmeier (2007) notes that language asymmetries are most pronounced for language production. Studies with splitbrain patients (i.e. patients in which the corpus callosum connecting the two sides of the brain is disconnected) for instance have found little evidence that the right hemisphere is involved in speech control (Gazzaniga, 1983). Federmeier (2007) (see also Wlotko and Federmeier (2007)) argues that the electrophysiological evidence on hemispheric asymmetries in cerebral function leads to the conclusion that the left hemisphere is biased towards predictive processing whereas the right hemisphere is biased towards bottom-up processing. She further argues that this left hemisphere bias for prediction arises because feedback connections play a larger role in left hemisphere processing since comprehension and production share resources only in this hemisphere. This increased interconnectivity, she suggests, allows "the system to rapidly generalize away from the input, and the resultant higher level activity is then fed back down, resulting in changes at lower levels that prepare the system to process likely upcoming stimuli" (Federmeier, 2007). Consistent with these proposals it has been found that listeners who show prediction effects in ERP studies also perform well in certain tasks, which (at least partly) involve language production 
processes. In the category fluency task, for example, participants are asked to produce as many members of a semantic category (e.g., animals) as they can in one minute. Federmeier found that performance in this task positively correlated with the amplitude of electrophysiological components associated with predictive language comprehension (Federmeier et al., 2010, 2002; but see Federmeier and Kutas (2005)). These are clearly interesting results and hemispheric differences in relation to predictive language processing undoubtedly merit further investigation (see also Wlotko and Federmeier $(2007,2013))$.

Some other evidence for the involvement of the language production system in the mechanisms underlying prediction in language comprehension comes from visual world eyetracking. Mani and Huettig (2012) presented 2-year-olds with sentences spoken by an adult speaker such as The boy eats $a$ big cake or The boy sees a big cake. While hearing these sentences the toddlers were looking at two-object displays (e.g., a cake and a bird). The average 2-year-olds predicted and fixated the target object before it was mentioned when they heard the semantically-constraining verb (eats) but not when they heard the neutral verb (sees). Toddlers' anticipatory fixations were significantly correlated with their productive vocabulary size. Children with large production vocabularies but not children with small production vocabularies anticipated the target objects. These data suggest that productionbased prediction mechanisms may be important in early language development.

There is also evidence that some higher-order deficits of speech production (e.g., agrammatism, amnesic or transcortical motor aphasia, see Ackermann et al. (2007), for further discussion) tend to occur in patients with cerebellar lesions. This raises the possibility for an involvement of the cerebellum in production-based prediction. Lesage et al. (2012), for example, argue that the cerebellum supports prediction in language processing. This is based on the (arguably rather vague) notion that the cerebellum is a "predictive machine" which estimates the outcome of motor commands. Lesage et al. applied repetitive transcranial magnetic stimulation (rTMS) to disrupt function in the right cerebellum. Participants showed (a small but significant) delay in eye fixations to target objects predicted by sentence context in a visual world eye-tracking experiment after cerebellar rTMS. They observed no effect on eye gaze in sentences in which targets could not be predicted. The prediction deficit, moreover, was absent in two control groups.

A recent study by Drake and Corley (2015) on the other hand could be interpreted as evidence against a strong version of production-based prediction (at least against the notion that production-based prediction involves phonological representations). They found that picture naming latencies were not influenced when the picture names overlapped phonologically with the predicted word in three picture naming experiments. These data suggest that if the production system is involved in predictive language processing it may not involve speech sound levels of representation.

In sum, production-based approaches present an interesting alternative mechanistic account of predictive language processing. They also naturally fit with predictive coding accounts in perception and action research as language comprehension can be seen as a form of action perception and language production as a form of action. The studies reviewed highlight that experimental evidence for the involvement of the production system in prediction so far is rather indirect and overall relatively sparse. This however is expected as production-based approaches to prediction are relatively recent.

4.1.4. PACS (production-, association-, combinatorial-, simulation-based prediction) - a multiple-mechanisms account of predictive language processing

The conclusion I draw from the research on the mechanisms of prediction is that even two systems accounts do not do justice to the complexity of anticipatory language processing (cf. Mani and Huettig, 2013). I suggest that our minds/brains employ many different mechanisms/strategies resulting in the preactivation/retrieval of linguistic input. I shall discuss four mechanisms (PACS: production-, association-, combinatorial-, and simulation-based prediction) which, I believe, are minimally required for a comprehensive account of predictive language processing. What are those mechanisms?

First, I suggest that comprehenders sometimes use their language production system to anticipate what another person is likely to say. My proposal is different from Pickering and Garrod's (2013) theory in that I assume that people use their fully-fledged production system for this rather than making use of a forward model. In other words, I argue that our frequent experiences of completing other's utterances "in our heads" is based on fully-specified production representations rather than the impoverished production presentations of a forward model.

Second, (as discussed above in relation to Kahneman's system 1) upcoming input is pre-activated by simple associative mechanisms (which may well be based on Hebbian learning). There is plenty of evidence that such priming is not limited to semantic knowledge but also involves phonological, orthographic and even non-linguistic information (e.g. Arias-Trejo and Plunkett, 2009, 2013; Federmeier and Kutas, 2001; Ganis et al., 1996; Grainger and Ferrand, 1996; Mani and Plunkett, 2011; Radeau et al., 1989, and many others).

Third, (as discussed in relation to Kahneman's system 2) there is evidence for the pre-activation of linguistic input via combinatorial mechanisms which are sensitive to multiple linguistic constraints and the building up of higher-order meaning (e.g. Kukona et al., 2011; Kuperberg, 2007). The question whether these combinatorial mechanisms involve partly separate systems for language comprehension and language production remains to be answered (see McCauley and Christiansen, 2011; Pickering and Garrod, 2013; and the up-coming special issue on Relations between Language Comprehension and Production of the Journal of Memory and Language for further discussion).

Fourth, I propose that linguistic input can be activated via event simulation. Tversky and Kahneman (1973) suggested already more than 40 years ago that people predict the likelihood of an upcoming event by how easy it is to simulate it. I suggest that we often use this event simulation heuristic to preactivate linguistic representations. This proposal makes contact with what is often called embodied language processing (see Barsalou (1999), Glenberg and Kaschak (2002) and Zwaan (2004, 2014)). Proponents of embodied cognition typically assume that all cognition is inherently embodied and that sensory 
representations (e.g. visual representations of a linguistic referent) are routinely accessed during language processing even in the absence of relevant perceptual input (e.g. Wassenburg and Zwaan, 2010; see Rommers et al. (2013), for a different view). My proposal is different in that I assume that we often use mental imagery (cf. Kosslyn et al., 2006; Paivio, 1990) to "perceptually" simulate events but that such simulations are not a necessary part of language comprehension. However, I do suggest that such event simulations play an important part of prediction in that they pre-activate linguistic representations and vice versa. This notion is similar to Moulton and Kosslyn's (2009) account according to which all mental imagery serves simulation (but see Pecher et al. (2009), Stanfield and Zwaan (2001) and Gallese, 2003, for a different view). Moulton and Kosslyn (2009) argue that imagery allows us to generate specific predictions based upon past experience. They point out that we can use mental imagery to predict events that we will never experience in the future (such as Einstein's imagery of travelling at light speed). How could imagery link up with linguistic representations? McQueen and Huettig (2014) presented evidence that seeing visual objects primes the semantic and phonological representations of related spoken words. There is no reason to believe that mental imagery of objects or events cannot do the same (see Moulton and Kosslyn (2009), for a similar argument and further discussion of the tight interplay between stored representations and imagery).

A recent set of experiments was conducted to start to explore the multiple mechanisms account. Hintz et al. (2014a) investigated the contribution of two of these mechanisms (associations and production-based prediction) to language-mediated anticipatory eye movements. In three visual world experiments participants looked at displays of four objects while listening to predictable sentences (e.g., "The man peels an apple") or nonpredictable sentences (e.g., "The man draws an apple"). Hintz et al. contrasted the contribution of general associations (as measured by a continued free verb-noun word association task in which participants are asked to read verbs one at a time and write down the first three nouns that come to their mind, cf. De Deyne et al., 2013) with the contribution of more specific semantic associations (as measured by verb-noun typicality ratings, see Ferretti et al. (2001), for further discussion). The assumption is that free word association ("general") tasks are sensitive to a number of different types of association (e.g., semantic, orthographic, phonological, visual, etc.) but that verb-noun typicality ratings more specifically tap certain semantic associations. Hintz et al. found that general verb-noun association strength was not a robust predictor of anticipatory eye gaze in any of the experiments. In all three experiments anticipatory eye gaze to the target objects correlated positively with the items' semantic associations. The probability of predictive eye gaze correlated also positively with participants' production fluency as measured in a separate verbal fluency task (cf. Van Der Elst et al., 2006) when the objects were presented before the verb was heard (Experiments 1 and 2) but not when participants were given only a short preview of the display (after the verb was heard, Experiment 3). These findings suggest that semantic associations are more important than more general associations for predictive language processing. Moreover these data indicate that the importance of specific anticipatory mechanisms is determined by the situational context in which prediction occurs (e.g., production-based prediction may be particularly potent with extended relevant visual input). This suggests that situational context (at least partly) determines the extent to which a particular prediction mechanism is employed.

Hintz et al. (2014b) further investigated how situational context may determine the use of production-based mechanisms. They tested the hypothesis that a task set including production in addition to comprehension encourages prediction compared to a task only including comprehension. Participants carried out a cross-modal naming task (Exp 1a), a self-paced reading task (Exp1 b) that did not include overt production, and a task (Exp 1c) in which naming and reading trials were interleaved. The same predictable and nonpredictable sentences were used in all three tasks (The man breaks a glass vs. The man borrows a glass). In Exp 1a, 54 participants listened to recordings of the sentences, which stopped before the target word. At this point in time a picture of the referent of the final word was shown. Participants were asked to name the objects as fast as possible. Analyses of their naming latencies revealed a significant naming advantage $(108 \mathrm{~ms})$ on predictable over non-predictable trials. In Exp 1b, 54 participants were asked to read the same sentences word-by-word in a self-paced reading task. There were no significant differences in reading times for the target word and spillover regions (which suggest that participants may not have predicted the target word). Exp 1c consisted of $50 \%$ naming trials and $50 \%$ reading trials, which were randomly intermixed. 54 participants named and read the same objects and sentences as in the previous experiments. The results showed a naming advantage (99 ms) on predictable over nonpredictable items and a positive correlation between the items' cloze probability and the reaction time in the naming task. Moreover, reading time analysis showed that with naming trials and reading trials interleaved participants were significantly faster $(19 \mathrm{~ms})$ at reading the spillover region on predictable relative to non-predictable items. These results suggest that predictive language processing can be modulated by the comprehenders' task set (see also Salverda et al. (2011), for task effects in language comprehension more generally). When the task set involves language production, as is often the case in natural conversation comprehenders appear to engage in prediction to a stronger degree than in "pure" comprehension tasks. The data do not show whether participants used the production system to predict in Experiment $1 \mathrm{c}$ when reading the sentences. However, the fact that they were faster reading the critical region of the sentences only when reading was intermixed with production trials is consisted with the idea that they used the production system to anticipate the target word also in the reading trials. Further research is needed to confirm this interpretation.

Finally, Hintz et al. (in preparation) contrasted the role of associations and event knowledge on prediction in an ERP study. Recall that Metusalem et al. (2012) examined the degree to which event knowledge is used for prediction. Their participants read passages consisting of two sentences, which established an event scenario. This was followed by a final sentence containing one of three target words: a highly predictable word, a semantically unexpected word that was related to the described event, or a semantically unexpected and event-unrelated word. Analyses of participants' ERPs showed that the predictable target words 
elicited a much smaller N400 than the unexpected and eventunrelated target words. However, the amplitude of the N400 elicited by the unexpected but event-related targets was significantly attenuated relative to the amplitude of the N400 elicited by the unexpected and event-unrelated targets. Metusalem and colleagues concluded that event knowledge is used for prediction. The authors rejected the possibility that simple word associations may have played a role based on a post-hoc analysis of word associations. Hintz et al. (In preparation) re-ran Metusalem et al.'s context manipulation and closely replicated their results (Experiment 1). In a second experiment two words from the eventestablishing sentences, which were most strongly associated with the unexpected but event-related targets in the final sentences, were selected. Each of the two associates was then placed in neutral carrier sentences. None of the other words in these carrier sentences was associatively related to the target words. Importantly, the two neutral carrier sentences did not build up a coherent event. ERPs were recorded while participants read the carrier sentences followed by the same final sentences as in Experiment 1. The results showed a global tendency of a critical difference between event-related and event-unrelated unexpected targets, which reached statistical significance only at parietal electrodes over the right hemisphere. These results suggest that associations alone cannot account for the N400 pattern observed in Experiment 1 (and in the study by Metusalem et al.) because the difference between event-related and eventunrelated conditions was larger when the sentences formed a coherent event relative to when they did not. However, because part of the effect remained, the findings suggest that during discourse reading both event knowledge activation and simple word associations jointly contribute to prediction. Note that the effect of event knowledge is consistent with both event simulation and combinatorial accounts described above. Further research is needed to distinguish the influence of the pre-activation of linguistic input via combinatorial mechanisms (sensitive to multiple linguistic constraints and the building up of higher-order meaning) from the activation of linguistic input via event simulation.

To conclude, I suggest that predictive language processing makes use of a set of diverse principles. I have described PACS (production-, association-, combinatorial-, and simulation-based prediction) mechanisms which I suggest are minimally required for a comprehensive account of predictive language processing. What is the nature of the relationship between these different mechanisms? I do not see these mechanisms as encapsulated but as constantly interrelated and interacting with each other. Associations feed into combinatorial mechanisms. Associative priming for instance leads to (faster) retrieval of associated representations/words which can be used by combinatorial mechanisms. The production system uses these combinatorial mechanisms but crucially there is more to language production than sequential combinatorial operations (which most likely are shared between production and comprehension). I conjecture that context (cf. Hintz et al., 2014a,b) provides the trigger for the use of the fully fledged production system for prediction (e.g. when people complete each other's utterances), i.e. scaling up prediction based on combinatorial mechanisms to fully-fledged production-based prediction. I suggest that associative mechanisms are also crucial in linking up the different PACS mechanisms. Event simulations may trigger associations between particular types of events and particular representations/ words/syntactic structures and vice versa. Event simulation may be more likely to occur during natural conversation thereby providing possible associative links between event simulation and production-based prediction. Note that sometimes the output of different PACS mechanisms will be in conflict (e.g. if associative mechanisms drive eye gaze to one visual referent and combinatorial mechanisms to another, cf. Kukona et al., 2011). The outcome of the comprehension process involving PACS mechanisms therefore greatly depends on the (linguistic and non-linguistic) context (cf. the constraint satisfaction approach to sentence processing, e.g. MacDonald et al., 1994). Clearly more research is needed to evaluate the interaction and integration of the PACS mechanisms. Few studies so far have directly contrasted postulated mechanisms of prediction in language processing. Future studies could usefully focus on the integration and interaction of these mechanisms. It would also be desirable to study these interactions in an implemented computational model.

Finally one might want to ask why our minds would work that way. Should not a unified/single system be preferred? What would be the benefit of multiple mechanisms for predictive language processing? On the one hand, there may be evolutionary advantages for minds who can predict upcoming linguistic input by making use of multiple routes/mechanisms to pre-activation of upcoming input. Such minds may have been able to draw behavioural consequences more rapidly than minds employing the same old strategy in every context/situation. On the other hand, it could well be that there is no evolutionary benefit. Evolution serves no purpose. The involvement of multiple mechanisms in predictive language processing may simply reflect evolutionary history. Some mechanisms may be evolutionarily older (e.g. simple associative mechanisms); others (e.g. combinatorial mechanisms involving more active forecasting) may be more recent. Some of the mechanisms leading to preactivation/retrieval of linguistic input may be by-products of mechanisms which have evolved for other purposes. In other words, there may not be a simple answer to the "why question" of prediction in language processing. Any answer to the "why question" will be more or less speculative given our current knowledge of the neurobiological foundations of the human mind.

\subsection{Mediating factors}

The significance of factors that might mediate prediction during language processing such as working memory and general cognitive efficiency has hardly been looked at. Moreover, the influence of such mediating factors may also be context-dependent and be contingent on the situation language users find themselves in. Languagemediated anticipatory eye gaze in the visual world, for example, requires the linking of visual objects to unfolding linguistic information, places, times, and each other. Individual differences in cognitive capacities such as working memory may be particularly important for anticipatory processing during such language-vision interactions (cf. Huettig et al., 2011). 


\subsubsection{Working memory and processing speed}

In a visual world eye-tracking study, Huettig and Janse (2012) presented Dutch participants with instructions such as "Kijk naar de Com $_{\text {afgebeelde piano }}$ (om" (look at the displayed piano) while viewing four objects. The Dutch articles ("het" or "de") were gender-marked and agreed in gender only with the target noun but not the three unrelated distractors. Therefore participants could use gender information from the article to predict the upcoming target objects. Participants fixated the target well before noun onset which strongly suggests that they anticipated the target objects. Individual differences in working memory were assessed using an auditory nonword repetition task as an index of verbal/ phonological short-term memory (Gathercole and Baddeley, 1996; Thorn and Gathercole, 1999) and a backwards digit span task (a more appropriate measure of the manipulation of items in memory rather than their storage and reproduction). Spatial working memory was assessed using the Corsi block tapping task (Corsi, 1972). General processing speed was measured using a digit-symbol substitution test and a letter comparison task. To make sure that potential individual differences do not just reflect non-verbal intelligence (often referred to as the " $g$-factor") Raven's Progressive Matrices was also administered to participants. Principal component analysis was then used to derive one Working Memory construct underlying the three memory measures (spatial short-term memory, auditory short-term memory, digit span), and one Processing Speed construct underlying the two speed measures (digit-symbol substitution and letter matching). The Working Memory construct correlated positively $(R=.39)$ and the Processing Speed construct negatively $(R=-.38)$ with anticipatory looks. The portion of explained variance (i.e. the change in $R^{2}$ ) uniquely attributable to Working Memory was .07, and that of Speed was .03. These findings suggest that enhanced working memory abilities support anticipatory spoken language processing whereas a decreased general processing speed has the opposite effect.

How may working memory influence language-mediated anticipatory eye movements? Huettig et al. (2011) argue that working memory connects long-term visual and linguistic representations to specific locations. This account predicts that working memory capacity plays an important role in languagemediated anticipatory eye movements. Objects in the visual display in visual world eye-tracking studies are assumed to be first encoded in a visuospatial type of working memory (cf. Pylyshyn, 1989; Cavanagh and Alvarez, 2005) which triggers perceptual hypotheses in long-term memory. Activation of these visual representations then cascades to "higher" levels of representation (e.g., activation of semantic and phonological representations) within a few hundreds of milliseconds (see Huettig and McQueen (2007) and McQueen and Huettig (2014) for experimental evidence). As a result object knowledge and associated linguistic knowledge (e.g., representations of the gender of the object names) are bound to the objects' locations within working memory. A similar chain of events is triggered from the linguistic input (e.g., hearing the article in the spoken instruction) and relevant representations (e.g., phonological, syntactic) will match up with those activated by the visual input. This activation is assumed to feed back to the object's location, which then increases the likelihood that a saccadic eye movement towards this location is triggered. In other words, the strength of activation of a particular representation translates into the probability of attending towards whatever shares those representations. Thus, better working memory abilities result in more efficient anticipatory eye gaze.

The Huettig and Janse (2012) study also suggests that individual differences in how quickly information is processed play an important role for predictive language processing. Note that processing speed is related to the speed with which neural signals are conducted along axons. Moreover, speed of neural transmission has been linked to the degree of myelination (Gutiérrez et al., 1995). This potential neural mechanism underlying processing speed and cognitive efficiency requires further investigation. Interestingly, the regression analysis suggests that non-verbal intelligence as measured by performance in Raven's progressive matrices does not contribute unique variance to language-mediated anticipatory eye gaze. It is therefore unlikely that a general " $g$-factor" (i.e. the notion that performance of individuals at many different cognitive tasks reflects one underlying factor) is related to language-mediated anticipatory eye movements.

It is important to point out here again that the influence of working memory and processing speed on anticipatory spoken language processing may be particularly strong in particular situational contexts, for example, when spoken language is used in relation to a co-present visual environment. This of course holds for many everyday situations when people give or receive instructions for action or talk about real world events. Nevertheless, the influence of individual differences in different cognitive abilities on anticipatory spoken language processing in other situations remains to be explored. It seems clear however that models of predictive language processing have to be revised to take mediating factors such as working memory and processing speed into account.

\subsubsection{Age}

Several studies have investigated the influence of age on predictive language processing. Rayner et al. (2006, 2009), based on the results of their reading studies in older adults, have suggested that older readers adopt a riskier reading strategy than younger adult readers. They found that older readers more often skip words, which could be interpreted as indicating that older adults predict more than younger adults to compensate for age-related cognitive decline. Federmeier and Kutas (2005) measured ERPs during word-by-word reading to investigate younger and older adults' semantic integration of final words in sentences differing in semantic constraint. They observed smaller and delayed effects of contextual constraint in older adults compared to young adults. Federmeier concluded that there may be a decreased reliance on predictive processing in older age (Federmeier et al., 2010; Huang et al., 2012; Wlotko and Federmeier, 2012). Wlotko and Federmeier (2012) (cf. Peelle et al., 2010) have speculated that older adults' decreased predictive language processing may either reflect less efficient functional connectivity or a decreased availability of neural resources. Huettig and Janse (2012) however recently found a small but positive role of age on predictive processing in their visual world eye-tracking task. This may be surprising given the findings of Federmeier and colleagues (Federmeier and Kutas, 2005; Huang et al., 2012). There are differences between the 
studies which may account for this discrepancy. The eyetracking study for instance investigated the anticipation of nouns with preceding article gender as a cue whereas the prediction in the ERP studies reflected an influence of semantic context. Semantic context effects are likely to build up over the course of the sentence whereas the cue in the eye-tracking task was a relatively local one. It is unlikely though that this difference in the prediction cue can fully account for the differences as detrimental influences of age were also found on rapid integration of information in adjective-noun units (Huang et al., 2012). It seems more likely that different studies have measured different influences of the interaction of an increasing life-long experience and cognitive decline in older adults. If age-related differences in processing speed and working memory are accounted for, age may in fact support predictive processing because of older adults' increased lifelong experience. Huettig and Janse found that older age is associated with poorer working memory and slower processing speed. It is only in their regression analysis, after having accounted for age effects on memory and speed that age turns out to be positively related to predictive processing. In other words, older adults may be more advanced language users than younger ones because of their lifelong experience (cf. Ramscar et al., 2014) but this advantage may often be overshadowed by age-related cognitive decline. Future studies could usefully explore this possibility further.

\subsubsection{Literacy}

For many human abilities it has been demonstrated that prediction is fundamentally linked to levels of expertise at the task at hand. Sport psychologists for instance observed that elite basketball players predict the success of free shots at baskets earlier and more accurately than amateurs. Findings like this are assumed to reflect the fine-tuning of anticipatory mechanisms that enable athletes to predict other's actions prior to their realization (Aglioti et al., 2008). Some recent research also provides strong evidence for a link between language abilities (i.e. reading levels) and prediction (i.e. anticipatory spoken language processing) using different types of participant populations (high and low literates, children, adults with dyslexia, and college students).

Mishra et al. (2012) presented Indian low and high literates with simple every-day spoken sentences containing a target word (e.g., "door"). While participants listened to the sentences they looked at a visual display of four objects (a target, i.e., the door, and three distractors). The spoken sentences were constructed to encourage anticipatory eye movements to the visual target objects. As in previous studies, the high literacy group started to shift their eye gaze to the target object well before target word onset. Crucially, the low literates did not anticipate the targets and looked at the target objects only once they heard the target being mentioned in the speech (more than a second later). These findings suggest that literacy modulates predictive spoken language processing.

Mani and Huettig (2014) provided converging evidence for the role of word reading skill in listener's anticipation of upcoming spoken language input by testing a different type of participant population, namely, 8-year-old German children at the cusp of literacy acquisition. They reasoned that if literacy really does impact predictive language processing, then children at this stage of literacy acquisition should be most susceptible to the effects of literacy on anticipation. 8-year-old German children were tested on their prediction of upcoming spoken language input in a similar visual world eye-tracking task. Mani and Huettig found a robust positive correlation between children's word reading skills and their prediction skills. Interestingly, their pseudo-word reading and meta-phonological awareness skills were not robust predictors of anticipation.

Given these literacy-related differences in anticipatory eye movements between low and high literate adults and in children learning to read, Huettig and Brouwer (in press) hypothesized that adults with dyslexia should show less efficient anticipatory eye movements than participants with no reading disorders. As predicted, they observed that adults with dyslexia anticipated the target objects much later than the control participants with no reading impairments. Moreover, participants' word reading scores correlated positively with their anticipatory eye movements providing further evidence for a link between reading abilities and anticipatory spoken language processing. Finally, James and Watson (2013) presented some evidence that literacy (as measured with performance in the Comparative Reading Habits questionnaire, Acheson et al., 2008, and the American Adult Reading Test, Blair and Spreen, 1989) is linked to predictive spoken language processing even among American college students.

How can this consistent influence of literacy on anticipation be explained? I believe that a full explanation is likely to be complex. Reading may lead to stronger associations also when spoken language input is processed. Such an explanation is in line with the notion of literacy as a proxy for experience. Consistent with this notion are the results of a study by Borovsky et al. (2012) who observed that children aged 3-10 with relatively high vocabulary knowledge were faster to anticipate target words than children with lower vocabulary knowledge. Production-related mechanism of prediction may also play a role. Written language experience in children for instance appears to increase the spoken production of relative clause sentences (Montag and MacDonald, 2014). Another possibility is that the process of learning orthographic representations during reading acquisition sharpens pre-existing lexical representations. According to this account orthographic exposure provides listeners with additional representations resulting in lexical representations becoming sharper and available more quickly during online speech processing (Mani and Huettig, 2014).

In short, predictive language processing is influenced by many individual differences. Working memory and processing speed/cognitive efficiency, age, and literacy have all been found to mediate anticipatory spoken language processing. So far we know very little about how these mediating factors influence each other and how they interface with the mechanism of predictive language processing described above. Theoretical models of predictive language processing though will only be complete if they can account for the complex interplay of multiple mechanisms and multiple mediating factors.

\section{When?}

The when question has so far received the least attention. It is however a very important question, especially given the 
claims that prediction is a (or the) fundamental principle underlying human information processing (Clark, 2013; Friston, 2005). Do people always predict?

This question is surprisingly difficult to answer. One reason is that most studies on predictive language processing have used very high cloze probability sentences (i.e. sentences in which the target word was extremely predictable). Most sentences we hear in our everyday lives are far less predictive. In other words our understanding of prediction in language understanding is mostly based on a comparison of performance between extremely predictive sentences and nonpredictive sentences. A notable exception is a recent study by Wlotko and Federmeier (2013). They used sentences with a continuous variation of cloze probability. ERPs were recorded while sentence-final words were presented in the left and right visual fields. Interestingly, right visual field (left hemisphere) items resulted in reduced $\mathrm{N} 400$ amplitudes over a broader range of predictability compared with left visual field (right hemisphere) items. Moreover, item-level analysis showed a statistically significant deviation from the linear relationship found for central visual field presentation. Wlotko and Federmeier (2013) concluded that N400 responses recorded with central field presentation therefore result from different contributions of both hemispheres and that neither hemisphere "on its own is sensitive to contextual predictability in an evenly graded manner." These results show how important it is to move away from conducting studies with high cloze probability sentences only. The findings of Wlotko and Federmeier (2013) also highlight the need to look not only at the ERPs to central field presentation but also at the separate contributions of left and right hemispheres. More generally these results are further support for multiple mechanisms of prediction or (in the words of Wlotko and Federmeier (2013)) "multiple processing modes implemented in parallel".

There are several studies which highlight the need to explore the "when question" more seriously. Low literate adults did not anticipate the target in Hindi adjective-particle-noun constructions (Mishra et al., 2012), two-year-olds with low production vocabulary did not anticipate target objects (Mani and Huettig, 2012), and older adults as a group did not use context predictively (Federmeier et al., 2012). These studies suggest that language comprehenders do not always predict.

Related to this, a need for further investigation of languagemediated prediction in non-student participant populations seems apparent. Most participants in studies on anticipatory language processing have been university students. It has lately been argued that the Western student participants used in most experiments in experimental psychology and cognitive neuroscience are the WEIRDest (Western Educated Industrialized Rich Democratic) people in the world and that it may be unsafe to draw more general conclusions about human behaviour from this participant population (Henrich et al., 2010; see also Arnett (2008)). The study of prediction I suggest has a particularly strong need for more diverse participant populations.

More cross-linguistic study is also required. So far only a tiny number of the world's thousands of languages have been explored. Such an investigation is important as languages differ dramatically at all levels of linguistic organization (Evans and Levinson, 2009). Exploring these differences is also important for investigating the mechanisms and mediating factors of anticipatory processing in a particular language. Individual differences approaches will also be useful to answer the "when question". Rommers et al. (in press) follow Underwood (1975) in arguing that psychological theories should be evaluated using individual-differences tests and that such tests should be the first step in the assessment of a theory (see also Kosslyn et al. (2002) and Vogel and Awh (2008)). Evidence that performance in two tasks is substantially correlated should be regarded as a "go-ahead signal" for a theory proposing that the cognitive components or abilities assessed in the tasks are related.

Finally, it is important to consider the methods that are used to investigate predictive language processing. Visual world eye-tracking experiments and ERP studies have become the methods of choice for the study of prediction over the last 20 years. Both paradigms have important strengths but also their own particular limitations, which are important to take into account when drawing conclusions from the experimental results.

An obvious limitation of visual world eye-tracking studies is that the speech that is presented must be related to the visual input. Moreover, the visual information presented in visual world eye-tracking studies may affect linguistic processing in subtle ways. The speed of pre-activation of up-coming spoken words may be affected through priming originating from the visual representations. In a series of lexical decision experiments, McQueen and Huettig (2014) found evidence for phonological inhibition for picture primes when the phonological onset was related to acoustically presented target pairs and semantic facilitation for same semantic category prime-target pairs. This shows that the recognition of spoken words can be affected by priming origination from viewing visual objects. The speed of pre-activation of up-coming spoken words may also be influenced because priming by vision-derived representations reduces ambiguity. Many words have more than one meaning ("pen", a writing implement or a cage) or more than one sense (e.g., "chicken", a whole animal or the meat) but identical phonology. Priming by a particular visual referent may speed up access of that meaning or sense. In other words, in visual word studies the representations of the objects are held in working memory. This may lead to the activation of the corresponding lexical representations and render certain concepts more potent than they would be in other situations. One way to minimize the impact of priming by vision-derived representations is to reduce the preview of the visual objects and present them only right before the spoken target word (e.g. $500 \mathrm{~ms}$ as in Rommers et al. (2013)). However, whether this is a suitable strategy will depend on the exact experimental question and design. The results of a visual world experiment may also lead one to the opposite conclusions (i.e. to underestimate the activation of lexical representations). Dahan and Tanenhaus (2004), for instance, presented Dutch phonological competitors (e.g., "bot", bone) of the target word (e.g., "bok", bock) in two conditions (semantically constraining sentential context vs. neutral sentential context). Phonological competitors were only fixated more than unrelated distractors when the target followed a neutral context but not when it followed a semantically constraining context. This does not necessarily mean that the lexical representations of the phonological 
competitor were not activated in the constraining context. It could simply mean that the activation of the phonological competitor was not measurable in the eye gaze. Eye gaze is a measure of overt attention and not a direct measure of the activation of lexical representations. It is important to note here however that predictive language processing in our daily interactions is often very similar to "choosing among a set of preactivated referents". In many conversations we talk about things in the here and now. In other words, the visual world paradigm has also its unique strengths. For the investigation of prediction when we talk about objects and events we see it is a particularly ecological valid paradigm. This captures many real world situations where people give or receive directions or instructions for action or talk about, say, the state of a messy room.

ERP studies have their own problematic issues. Often written words are presented one-by-one in a relatively slow manner. Note in this regard that the reduction of the ERP N400 component does not necessarily indicate prediction of upcoming words. Some studies (Connolly and Phillips, 1994; Van Den Brink et al., 2001) investigated this issue by making use of the temporal unfolding of speech. Sentence context in these studies was highly constraining towards particular target words (e.g., "The gambler had a streak of bad..."). Crucially, the unexpected target word overlapped phonologically at word onset sometimes with the expected word (e.g., luggage). An earlier negativity was observed if the unexpected word had no initial phonological overlap with the expected word. Although these kinds of results are typically interpreted as reflecting prediction of upcoming words, they could also be explained by postulating a matching process between expected words and candidate words at a post-lexical stage (cf. Van Den Brink et al., 2001). In other words, most ERP N400 studies on predictive language processing do actually not provide unequivocal evidence for prediction leaving them open to the (as Kutas et al. (2011) put it) "oh, it's just integration criticism". Note however that a few ERP studies have succeeded in getting around this problem. The nice manipulation in these studies is that the electrophysiological sign of anticipation preceded the anticipated target word (DeLong et al., 2005, Van Berkum et al., 2005; Wicha et al., 2004). DeLong et al. (2005) for instance took advantage of the fact that in English the indefinite articles $a$ and an are used depending on the initial phoneme of the noun. Participants read sentences such as "The day was breezy so the boy went outside to fly ... a kite/an airplane ... in the park". In this sentence a kite is highly predicted but an airplane is not. DeLong et al. observed a smaller $\mathrm{N} 400$ for a kite than an airplane to the articles. The fact that the attenuated N400 was observed to the article (i.e. before the predicted noun) suggests that the N400 reflected prediction rather than "mere" integration (as both $a$ and an should have been equally easy to be integrated). It is still the case however that most ERP studies investigating predictive language processing measure the N400 to the predicted target words rather than before. It would be useful if future studies follow the experimental design of DeLong, Wicha, and Van Berkum and colleagues so that prediction and integration explanations can be distinguished. If such a design is not possible a useful strategy would be to provide converging evidence from two different methods (e.g. ERP and eyetracking as in the Rommers et al., 2013, study).

\section{Conclusion}

The reviewed literature makes clear that many aspects of predictive language processing have been explored. Some substantial progress has been made (we know for example quite a lot about the cues that are used for anticipation), yet it is also apparent that there are many gaps in our understanding, which requires further systematic research. We know relatively little about the contents of prediction. How far does pre-activation cascade and to what extent is it situation-dependent? An important advance which has been made over recent years is that researchers focus more directly on the mechanisms underlying predictive language processing. I suggest that inclusion of the PACS (production-, association-, combinatorial-, and simulation-based prediction) mechanisms is a minimum requirement for a comprehensive account of predictive language processing. The experimental evidence considered here also highlights that future research needs to consider more the individual differences which mediate anticipatory processing. I have discussed the role of working memory, cognitive efficiency, age, and literacy which all influence prediction. There are many other individual differences which are likely to play a role. A final important consideration concerns the limits of predictive language processing. Are our brains really prediction machines? Do we really constantly predict at all levels of linguistic (and nonlinguistic) structure (cf. Clark, 2013; Friston, 2010)? Perhaps prediction is something which happens when cognitive systems have plenty of resources available. According to this notion prediction is strongly linked to high proficiency levels at the task at hand. The strong influences of literacy on anticipatory language processing discussed above point clearly in that direction. Perhaps prediction occurs less or not at all in challenging situations (cf. Brouwer et al., 2013) and in less proficient language users. Perhaps prediction occurs more in such situations (and more for challenged language users) but I believe these are the kinds of questions that deserve much more exploration. I conjecture that it is important to seriously evaluate the following question (even if it appears to go against the current main stream view): Is prediction an important aspect but perhaps not a fundamental principle of language processing and the human mind?

\section{R E F E R E N C E S}

Acheson, D.J., Wells, J.B., MacDonald, M.C., 2008. New and updated tests of print exposure and reading abilities in college students. Behav. Res. Methods 40 (1), 278-289.

Ackermann, H., Mathiak, K., Riecker, A., 2007. The contribution of the cerebellum to speech production and speech perception: clinical and functional imaging data. The Cerebellum 6, 202-213. Aglioti, S.M., Cesari, P., Romani, M., Urgesi, C., 2008. Action anticipation and motor resonance in elite basketball players. Nat. Neurosci. 11, 1109-1116.

Altmann, G.T.M., Kamide, Y., 1999. Incremental interpretation at verbs: restricting the domain of subsequent reference. Cognition 73, 247-264.

Altmann, G., Mirković, J., 2009. Incrementality and prediction in human sentence processing. Cogn. Sci. 33 (4), 583-609. 
Arbib, M.A., 2005. From monkey-like action recognition to human language: an evolutionary framework for neurolinguistics. Behav. Brain Sci. 28 (02), 105-124.

Arias-Trejo, N., Plunkett, K., 2009. Lexical-semantic priming effects during infancy. Philos. Trans. R. Soc. B: Biol. Sci. 364 (1536), 3633-3647.

Arias-Trejo, N., Plunkett, K., 2013. What's in a link: associative and taxonomic priming effects in the infant lexicon. Cognition 128 (2), 214-227.

Arnett, J., 2008. The neglected 95\%: why American psychology needs to become less American. Am. Psychol. 63, 602-614.

Bar, M., 2007. The proactive brain: using analogies and associations to generate predictions. Trends Cogn. Sci. 11 (7), 280-289.

Bar, M., 2009. The proactive brain: memory for predictions. Philos. Trans. R. Soc. B: Biol. Sci. 364 (1521), 1235-1243.

Barsalou, L.W., 1999. Perceptions of perceptual symbols. Behav. Brain Sci. 22 (04), 637-660.

Blair, J.R., Spreen, O., 1989. Predicting premorbid IQ: a revision of the National Adult Reading Test. Clin. Neuropsychol. 3 (2), 129-136.

Borovsky, A., Elman, J.L., Fernald, A., 2012. Knowing a lot for one's age: vocabulary skill and not age is associated with anticipatory incremental sentence interpretation in children and adults. J. Exp. Child Psychol. 112 (4), 417-436.

Brady, J.P., 1971. Metronome-conditioned speech retraining for stuttering. Behavior Therapy 2 (2), 129-150.

Brouwer, S., Mitterer, H., Huettig, F., 2013. Discourse context and the recognition of reduced and canonical spoken words. Appl. Psycholinguist. 34, 519-539.

Cavanagh, P., Alvarez, G.A., 2005. Tracking multiple targets with multifocal attention. Trends Cogn. Sci. 9 (7), 349-354.

Chang, F., Dell, G.S., Bock, K., 2006. Becoming syntactic. Psychol, Rev. 113 (2), 234.

Chang, F., Kidd, E., Rowland, C.F., 2013. Prediction in processing is a by-product of language learning. Behav. Brain Sci. 36 (04), 350-351.

Clark, A., 2013. Whatever next? Predictive brains, situated agents, and the future of cognitive science. Behav. Brain Sci. 36 (03), 181-204.

Clark, H.H., 1996. Using Language. Cambridge University Press, Cambridge.

Clark, H.H., Wilkes-Gibbs, D., 1986. Referring as a collaborative process. Cognition 22 (1), 1-39.

Connolly, J., Phillips, N., 1994. Event-related potential components reflect phonological and semantic processing of the terminal word of spoken sentences. J. Cogn. Neurosci. 6 (3), 256-266.

Conway, C.M., Bauernschmidt, A., Huang, S.S., Pisoni, D.B., 2010. Implicit statistical learning in language processing: word predictability is the key. Cognition 114 (3), 356-371.

Copland, D.A., De Zubicaray, G.I., McMahon, K., Wilson, S.J., Eastburn, M., Chenery, H.J., 2003. Brain activity during automatic semantic priming revealed by event-related functional magnetic resonance imaging. Neuroimage 20 (1), 302-310.

Corsi, P.M., 1972. Human Memory and the Medial Temporal Region of the Brain (Ph.D.). McGill University.

Dahan, D., Tanenhaus, M.K., 2004. Continuous mapping from sound to meaning in spoken-language comprehension: immediate effects of verb-based thematic constraints. J. Exp. Psychol.: Learn. Mem. Cogn. 30 (2), 498-513.

De Deyne, S., Navarro, D.J., Storms, G., 2013. Better explanations of lexical and semantic cognition using networks derived from continued rather than single-word associations. Behav. Res. Methods 45, 480-498.

Dell, G.S., Chang, F., 2014. The P-chain: relating sentence production and its disorders to comprehension and acquisition. Philos. Trans. R. Soc. B: Biol. Sci. 369 (1634), 20120394.

DeLong, K., Urbach, T., Kutas, M., 2005. Probabilistic word preactivation during language comprehension inferred from electrical brain activity. Nat. Neurosci. 8 (8), 1117-1121.
De Ruiter, J.P., Mitterer, H., Enfield, N.J., 2006. Predicting the end of a speaker's turn; a cognitive cornerstone of conversation. Language 82 (3), 515-535.

Drake, E., Corley, M., 2015. Effects in production of word preactivation during listening: are listener-generated predictions specified at a speech-sound level?. Mem. Cogn 43, 111-120.

Duncan, J., 2010. The multiple-demand (MD) system of the primate brain: mental programs for intelligent behaviour. Trends Cogn. Sci. 14 (4), 172-179.

Ehrlich, S.E., Rayner, K., 1981. Contextual effects on word perception and eye movements during reading. J. Verbal Learn. Verbal Behav. 20, 641-655.

Elman, J.L., 1990. Finding structure in time. Cogn. Sci. 14 (2), 179-211.

Evans, N., Levinson, S.C., 2009. The myth of language universals: Language diversity and its importance for cognitive science. Behavioral and brain sciences 32 (05), 429-448.

Fadiga, L., Craighero, L., Buccino, G., Rizzolatti, G., 2002. Speech listening specifically modulates the excitability of tongue muscles: a TMS study. Eur. J. Neurosci. 15 (2), 399-402.

Federmeier, K.D., 2007. Thinking ahead: the role and roots of prediction in language comprehension. Psychophysiology 44 (4), 491-505.

Federmeier, K., McLennan, D.B., De Ochoa, E., Kutas, M., 2002. The impact of semantic memory organization and sentence context information on spoken language processing by younger and older adults: an ERP study. Psychophysiology 39, 133-146.

Federmeier, K.D., Kutas, M., 1999. A rose by any other name: longterm memory structure and sentence processing. J. Mem. Lang. 41, 469-495.

Federmeier, K.D., Kutas, M., 2001. Meaning and modality: influences of context, semantic memory organization, and perceptual predictability on picture processing. J. Exp. Psychol.: Learn. Mem. Cogn. 27 (1), 202-224.

Federmeier, K.D., Kutas, M., 2005. Aging in context: age-related changes in context use during language comprehension. Psychophysiology 42 (2), 133-141.

Federmeier, K.D., Kutas, M., Schul, R., 2010. Age-related and individual differences in the use of prediction during language comprehension. Brain Lang. 115 (3), 149-161.

Friederici, A.D., Rueschemeyer, S.A., Hahne, A., Fiebach, C.J., 2003. The role of left inferior frontal and superior temporal cortex in sentence comprehension: localizing syntactic and semantic processes. Cereb. Cortex 13 (2), 170-177.

Friston, K., 2005. A theory of cortical responses. Philosophical transactions of the Royal Society B: Biological sciences 360 (1456), 815-836.

Frisson, S., Rayner, K., Pickering, M.J., 2005. Effects of contextual predictability and transitional probability on eye movements during reading. J. Exp. Psychol.: Learn. Mem. Cogn. 31, 862-877.

Friston, K.J., 2010. The free-energy principle: a unified brain theory?. Nat. Rev. Neurosci. 11 (2), 127-138.

Gallese, V., 2003. The manifold nature of interpersonal relations: the quest for a common mechanism. Philos. Trans. R. Soc. Lond. Ser. B: Biol. Sci. 358 (1431), 517-528.

Ganis, G., Kutas, M., Sereno, M.L., 1996. The search for "common sense": an electrophysiological study of the comprehension of words and pictures in reading. J. Cogn. Neurosci. 8 (2), 89-106.

Gathercole, S.E., Baddeley, A.D., 1996. The Children's Test of Nonword Repetition. Psychological Corporation, London, UK.

Gazzaniga, M.S., 1983. Right hemisphere language following brain bisection: a 20-year perspective. Am. Psychol. 38 (5), 525.

Glenberg, A.M., Kaschak, M.P., 2002. Grounding language in action. Psychon. Bull. Rev. 9 (3), 558-565.

Grainger, J., Ferrand, L., 1996. Masked orthographic and phonological priming in visual word recognition and naming: cross-task comparisons. J. Mem. Lang. 35 (5), 623-647. 
Gutiérrez, R., Boison, D., Heinemann, U., Stoffel, W., 1995. Decompaction of CNS myelin leads to a reduction of the conduction velocity of action potentials in optic nerve. Neurosci. Lett. 195 (2), 93-96.

Hagoort, P., Hald, L., Bastiaansen, M., Petersson, K.M., 2004. Integration of word meaning and world knowledge in language comprehension. Science 304 (5669), 438-441.

Halgren, E., Dhond, R.P., Christensen, N., Van Petten, C., Marinkovic, K., Lewine, J.D., Dale, A.M., 2002. N400-like magnetoencephalography responses modulated by semantic context, word frequency, and lexical class in sentences. Neuroimage 17 (3), 1101-1116.

Hayhoe, M.M., Shrivastava, A., Mruczek, R., Pelz, J.B., 2003. Visual memory and motor planning in a natural task. J. Vis. 3 (1), 49-63.

Hellige, Joseph B., 1993. Hemispheric Asymmetry: What's Right and What's Left. Vol. 6. Harvard University Press.

Henrich, J., Heine, S.J., Norenzayan, A., 2010. The weirdest people in the world?. Behav. Brain Sci. 33, 61-135.

Hintz, F., Meyer, A.S., \& Huettig, F. 2014a. The influence of verbspecific featural restrictions, word associations, and production-based mechanisms on language-mediated anticipatory eye movements. In: Proceedings of the 27th Annual CUNY Conference on Human Sentence Processing, Ohio State University, Columbus/Ohio.

Hintz, F., Meyer, A.S., \& Huettig, F. 2014b. Prediction using production or production engaging prediction? In: Proceedings of the 20th Architectures and Mechanisms for Language Processing Conference (AMLAP 2014), Edinburgh, Scotland.

Hintz, F., Meyer, A.S., \& Huettig, F. 2015. Event knowledge and simple word associations jointly influence predictive processing during discourse comprehension, In preparation.

Huang, H.-W., Meyer, A.M., Federmeier, K.D., 2012. A "concrete view" of aging: event related potentials reveal age-related changes in basic integrative processes in language. Neuropsychologia 50, 26-35.

Huettig, F., Altmann, G.T.M., 2005. Word meaning and the control of eye fixation: semantic competitor effects and the visual world paradigm. Cognition 96 (1), B23-B32.

Huettig, F. and Brouwer, S., in press. Delayed anticipatory spoken language processing in adults with dyslexia - Evidence from eye-tracking. Dyslexia.

Huettig, F., \& Janse, E. 2012. Anticipatory eye movements are modulated by working memory capacity: evidence from older adults. In: Proceedings of the 18th Architectures and Mechanisms for Language Processing Conference, Riva del Garda, Italy.

Huettig, F., McQueen, J.M., 2007. The tug of war between phonological, semantic, and shape information in languagemediated visual search. J. Mem. Lang. 54, 460-482.

Huettig, F., Olivers, C.N., Hartsuiker, R.J., 2011. Looking, language, and memory: bridging research from the visual world and visual search paradigms. Acta Psychol. 137 (2), 138-150.

Huettig, F., Rommers, J., Meyer, A.S., 2011. Using the visual world paradigm to study language processing: a review and critical evaluation. Acta Psychol. 137, 151-171.

Huettig, F., Singh, N., Mishra, R.K., 2011. Language-mediated visual orienting behavior in low and high literates. Front. Psychol. 2, 285.

Hunnius, S., Bekkering, H., 2010. The early development of object knowledge: a study of Infants' visual anticipations during action observation. Dev. Psychol. 46, 446-454.

Jackendoff, R., 2002. Foundations of Language: Brain, Meaning, Grammar, Evolution. Oxford University Press.

Jackendoff, R., 2007. A parallel architecture perspective on language processing. Brain Res. 1146, 2-22.

James, A., \& Watson, D. 2013. Language experience and prediction in auditory sentence comprehension. In: Proceedings of the 19th Architectures and Mechanisms for Language Processing Conference, Marseille, France.
James, W., 1890. The Principles of Psychology. Henry Holt. Kahneman, D., 2011. Thinking, Fast and Slow. Macmillan.

Kaiser, E., Trueswell, J.C., 2004. The role of discourse context in the processing of a flexible word-order language. Cognition 94 (2), 113-147.

Kamide, Y., Altmann, G.T.M., Haywood, S.L., 2003. Prediction and thematic information in incremental sentence processing: evidence from anticipatory eye movements. J. Mem. Lang. 49, 133-156.

Kamide, Y., Scheepers, C., Altmann, G.T.M., 2003. Integration of syntactic and semantic information in predictive processing: crosslinguistic evidence from German and English. J. Psycholinguist. Res. 32, 37-55.

Kiehl, K.A., Laurens, K.R., Liddle, P.F., 2002. Reading anomalous sentences: an event-related fMRI study of semantic processing. Neuroimage 17 (2), 842-850.

Knoeferle, P., Crocker, M.W., Scheepers, C., Pickering, M.J., 2005. The influence of immediate visual context on incremental thematic role-assignment: evidence from eye-movements in depicted events. Cognition 95 (1), 95-127.

Knoeferle, P., Crocker, M.W., 2007. The influence of recent scene events on spoken comprehension: evidence from eye movements. J. Mem. Lang. 57 (4), 519-543.

Kosslyn, S.M., Cacioppo, J.T., Davidson, R.J., Hugdahl, K., Lovallo, W.R. Spiegel, D., Rose, R., 2002. Bridging psychology and biology - the analysis of individuals in groups. Am. Psychol. 57 (5), 341-351.

Kosslyn, S.M., Thompson, W.L., Ganis, G., 2006. The Case for Mental Imagery. Oxford University Press.

Kotz, S.A., Cappa, S.F., Von Cramon, D.Y., Friederici, A.D., 2002. Modulation of the lexical-semantic network by auditory semantic priming: an event-related functional MRI study. Neuroimage 17 (4), 1761-1772.

Kotz, A.A., Schwartze, M., Schmidt-Kassow, M., 2009. Non-motor basal ganglia functions: a review and proposal for a model of sensory predictability in auditory language perception. Cortex 45, 982-990.

Kuperberg, G.R., 2007. Neural mechanisms of language comprehension: challenges to syntax. Brain Res. 1146, 23-49.

Kuperberg, G.R., Holcomb, P.J., Sitnikova, T., Greve, D., Dale, A.M., Caplan, D., 2003. Distinct patterns of neural modulation during the processing of conceptual and syntactic anomalies. J. Cogn. Neurosci. 15 (2), 272-293.

Kukona, A., Fang, S.Y., Aicher, K.A., Chen, H., Magnuson, J.S., 2011. The time course of anticipatory constraint integration. Cognition 119 (1), 23-42.

Kutas, M., DeLong, K.A., Smith, N.J., 2011. A look around at what lies ahead: Prediction and predictability in language processing. Predictions in the brain: Using our past to generate a future, 190-207.

Kutas, M., Federmeier, K.D., 2011. Thirty years and counting: finding meaning in the N400 component of the event-related brain potential (ERP). Annu. Rev. Psychol. 62, 621-647.

Kutas, M., Hillyard, S.A., 1984. Brain potentials during reading reflect word expectancy and semantic association. Nature 307, 161-163.

Keller, P.E., Koch, I., 2008. Action planning in sequential skills: relations to music performance. Q. J. Exp. Psychol. 61 (2), 275-291.

Kilner, J.M., Vargas, C., Duval, S., Blakemore, S.J., Sirigu, A., 2004. Motor activation prior to observation of a predicted movement. Nat. Neurosci. 7, 1299-1301.

Land, M., Mennie, N., Rusted, J., 1999. The roles of vision and eye movements in the control of activities of daily living. Perception 28, 1311-1328.

Land, M.F., Furneaux, S., 1997. The knowledge base of the oculomotor system. Philos. Trans. R. Soc. Lond. Ser. B-Biol. Sci. 352 (1358), 1231-1239.

Land, M.F., Lee, D.N., 1994. Where we look when we steer. Nature 369 (6483), 742-744.

Laszlo, S., Federmeier, K.D., 2009. A beautiful day in the neighborhood: an event-related potential study of lexical relationships in sentence context. J. Mem. Lang. 61, 326-338. 
Lesage, E., Morgan, B.E., Olson, A.C., Meyer, A.S., Miall, R.C., 2012. Cerebellar rTMS disrupts predictive language processing. Curr. Biol. 22 (18), R794-R795.

Mani, N., Plunkett, K., 2011. Phonological priming and cohort effects in toddlers. Cognition 121 (2), 196-206.

Matsumoto, A., Iidaka, T., Haneda, K., Okada, T., Sadato, N., 2005. Linking semantic priming effect in functional MRI and eventrelated potentials. Neuroimage 24 (3), 624-634.

MacDonald, M.C., Pearlmutter, N.J., Seidenberg, M.S., 1994. The lexical nature of syntactic ambiguity resolution. Psychological review 101 (4).

Montag, J.L., \& MacDonald, M.C. 2014. Text exposure may affect relative clause use in children and adults. In: Proceedings of the 27th Annual CUNY Conference on Human Sentence Processing, Ohio State University, Columbus/Ohio (US).

McDonald, S.A., Shillcock, R.C., 2003. Low-level predictive inference in reading: the influence of transitional probabilities on eye movements. Vis. Res. 43, 1735-1751.

McIntosh, G.C., Brown, S.H., Rice, R.R., Thaut, M.H., 1997. Rhythmic auditory-motor facilitation of gait patterns in patients with Parkinson's disease. J. Neurol. Neurosurg. Psychiatry 62, 22-26.

McFarland, D.H., 2001. Respiratory markers of conversational interaction. J. Speech Lang. Hear. Res. 44, 128-143.

McQueen, J.M., Huettig, F., 2014. Interference of spoken word recognition through phonological priming from visual objects and printed words. Atten. Percept. Psychophys. 76 (1), 190-200.

Ferretti, T.R., McRae, K., Hatherell, A., 2001. Integrating verbs, situation schemas, and thematic role concepts. J. Mem. Lang. 44 (4), 516-547.

Mani, N., Huettig, F., 2012. Prediction during language processing is a piece of cake - but only for skilled producers. J. Exp. Psychol.: Hum. Percept. Perform. 38 (4), 843-847.

Mani, N., Huettig, F., 2013. Towards a complete multiplemechanism account of predictive language processing [Commentary on Pickering \& Garrod]. Behav. Brain Sci. 36, 365-366.

Mani, N., Huettig, F., 2014. Word reading skill predicts anticipation of upcoming spoken language input: a study of children developing proficiency in reading. J. Exp. Child Psychol. 126, 264-279.

McCauley, S., \& Christiansen, M.H. 2011. Learning simple statistics for language comprehension and production: the CAPPUCCINO model. In: Carlson, L., Hölscher, C., Shipley, T. (Eds.), Proceedings of the 33rd Annual Conference of the Cognitive Science Society, Cognitive Science Society, Austin, TX, pp. 1619-1624.

McQueen, J.M., Huettig, F., 2014. Interference of spoken word recognition through phonological priming from visual objects and printed words. Atten. Percept. Psychophys. 76 (1), 190-200.

Mennie, N., Hayhoe, M., Sullivan, B., 2007. Look ahead fixations: anticipatory eye movements in natural tasks. Exp. Brain Res. 179 (3), 427-442.

Metusalem, R., Kutas, M., Urbach, T.P., Hare, M., McRae, K., Elman, J.L., 2012. Generalized event knowledge activation during online sentence comprehension. J. Mem. Lang. 66 (4), 545-567.

Mishra, R.K., Singh, N., Pandey, A., Huettig, F., 2012. Spoken language-mediated anticipatory eye movements are modulated by reading ability: evidence from Indian low and high literates. J. Eye Mov. Res. 5 (1), 1-10.

Misyak, J.B., Christiansen, M.H., Bruce Tomblin, J., 2010. Sequential expectations: the role of prediction-based learning in language. Top. Cogn. Sci. 2 (1), 138-153.

Moulton, S.T., Kosslyn, S.M., 2009. Imagining predictions: mental imagery as mental emulation. Philos. Trans. R. Soc. B: Biol. Sci. 364 (1521), 1273-1280.

Nation, K., Marshall, C.M., Altmann, G.T.M., 2003. Investigating individual differences in children's real-time sentence comprehension using language-mediated eye movements. J. Exp. Child Psychol. 86, 314-329.

Ni, W., Constable, R., Mencl, W., Pugh, K., Fulbright, R., Shaywitz, S., Shankweiler, D., 2000. An event-related neuroimaging study distinguishing form and content in sentence processing. J. Cogn. Neurosci. 12 (1), 120-133.

Pardo, J., 2006. On phonetic convergence during conversational interaction. J. Acoust. Soc. Am. 119, 2382-2393.

Paivio, A., 1990. Mental Representations: A Dual Coding Approach. Oxford University Press.

Pecher, D., van Dantzig, S., Schifferstein, H.N., 2009. Concepts are not represented by conscious imagery. Psychon. Bull. Rev. 16 (5), 914-919.

Peelle, J.E., Troiani, V., Wingfield, A., Grossman, M., 2010. Neural processing during older adults' comprehension of spoken sentences: age differences in resource allocation and connectivity. Cereb. Cortex 20, 773-782.

Pelucchi, B., Hay, J.F., Saffran, J.R., 2009. Learning in reverse: eightmonth-old infants track backward transitional probabilities. Cognition 113 (2), 244-247.

Perruchet, P., Desaulty, S., 2008. A role for backward transitional probabilities in word segmentation?. Mem. Cognit. 36 (7), 1299-1305.

Pickering, M.J., Garrod, S., 2004. Toward a mechanistic psychology of dialogue. Behav. Brain Sci. 27 (02), 169-190.

Pickering, M.J., Garrod, S., 2007. Do people use language production to make predictions during comprehension?. Trends Cogn. Sci. 11, 105-110.

Pickering, M.J., Garrod, S., 2013. An integrated theory of language production and comprehension. Behav. Brain Sci. 36 (04), 329-347.

Popper, K.R., 1959. The Logic of Scientific Discovery. Hutchinson, London.

Posner, M.I., 1980. Orienting of attention. Q. J. Exp. Psychol. 32 (1), 3-25.

Prinz, W., 1990. In: A common coding approach to perception and action. Springer, Berlin Heidelberg.

Prinz, W., 2006. What re-enactment earns us. Cortex 42 (4), 515-517.

Pylyshyn, Z., 1989. The role of location indexes in spatial perception: a sketch of the FINST spatial-index model. Cognition 32 (1), 65-97.

Radeau, M., Morais, J., Dewier, A., 1989. Phonological priming in spoken word recognition: task effects. Mem. Cognit. 17 (5), 525-535.

Ramnani, N., Miall, R.C., 2004. A system in the human brain for predicting the actions of others. Nat. Neurosci. 7 (1), 85-90.

Ramscar, M., Hendrix, P., Shaoul, C., Milin, P., Baayen, H., 2014. The myth of cognitive decline: non-linear dynamics of lifelong learning. Top. Cogn. Sci. 6 (1), 5-42.

Rayner, K., Clifton Jr., C., 2009. Language processing in reading and speech perception is fast and incremental: implications for event-related potential research. Biol. Psychol. 80 (1), 4-9.

Rayner, K., Reichle, E.D., Stroud, M.J., Williams, C.C., Pollatsek, A., 2006. The effect of word frequency, word predictability, and font difficulty on the eye movements of young and older readers. Psychol. Aging 21 (3), 448-465.

Rayner, K., Well, A.D., 1996. Effects on contextual constraint on eye movements in reading: a further examination. Psychon. Bull. Rev. 3, 504-509.

Romberg, A.R., Saffran, J.R., 2010. Statistical learning and language acquisition. Wiley Interdiscip. Rev.: Cogn. Sci. 1 (6), 906-914.

Rommers, J., Meyer, A. S. and Huettig, F. (in press). Verbal and nonverbal predictors of language-mediated anticipatory eye movements. Atten Percept Psychophys. http://dx.doi.org/10. 3758/s13414-015-0873-X.

Rommers, J., Meyer, A.S., Huettig, F., 2013. Object shape and orientation do not routinely influence performance during language processing. Psychol. Sci. 24 (11), 2218-2225.

Rommers, J., Meyer, A.S., Praamstra, P., Huettig, F., 2013. The contents of predictions in sentence comprehension: activation of the shape of objects before they are referred to. Neuropsychologia 51 (3), 437-447. 
Rossell, S.L., Price, C.J., Nobre, A.C., 2003. The anatomy and time course of semantic priming investigated by fMRI and ERPs. Neuropsychologia 41 (5), 550-564.

Rothermich, K., Kotz, S.A., 2013. Predictions in speech comprehension:fMRI evidence on the meter-semantic interface. NeuroImage 70, 89-100.

Rowland, C., Chang, F., Ambridge, B., Pine, J.M., Lieven, E.V., 2012. The development of abstract syntax: evidence from structural priming and the lexical boost. Cognition 125 (1), 49-63.

Saffran, J.R., Aslin, R.N., Newport, E.L., 1996. Statistical learning by 8-month-old infants. Science 274 (5294), 1926-1928.

Salverda, A.P., Brown, M., Tanenhaus, M.K., 2011. A goal-based perspective on eye movements in visual world studies. Acta Psychol. 137 (2), 172-180.

Scott, S.K., McGettigan, C., Eisner, F., 2009. A little more conversation, a little less action-candidate roles for the motor cortex in speech perception. Nat. Rev. Neurosci. 10 (4), 295-302.

Schiller, N.O., Horemans, I., Ganushchak, L., Koester, D., 2009. Event-related brain potentials during the monitoring of speech errors. NeuroImage 44 (2), 520-530.

Sebanz, N., Knoblich, G., 2009. Prediction in joint action: what, when, and where. Top. Cogn. Sci. 1, 353-367.

Sebanz, N., Knoblich, G., Prinz, W., 2003. Representing others' actions: just like one's own?. Cognition 88, B11-B21.

Sebanz, N., Knoblich, G., Prinz, W., 2005. How two share a task: co-representing stimulus-response mappings. J. Exp. Psychol.: Hum. Percept. Perform. 31, 1234-1246.

Staub, A., Clifton Jr., C., 2006. Syntactic prediction in language comprehension: evidence from either... or. J. Exp. Psychol.: Learn. Mem. Cogn. 32 (2), 425.

Stanfield, R.A., Zwaan, R.A., 2001. The effect of implied orientation derived from verbal context on picture recognition. Psychol. Sci. 12 (2), 153-156.

Stanovich, K.E., West, R.F., 2000. Advancing the rationality debate. Behav. Brain Sci. 23 (05), 701-717.

St Clair, M., Monaghan, P., Ramscar, M., 2009. Relationships between language structure and language learning: the suffixing preference and grammatical categorization. Cogn. Sci. 33, 1317-1329.

Thorn, A.S.C., Gathercole, S.E., 1999. Language-specific knowledge and short-term memory in bilingual and nonbilingual children. Q. J. Exp. Psychol. Sect. A 52 (2), 303-324.

Tversky, A., Kahneman, D., 1973. Availability: a heuristic for judging frequency and probability. Cogn. Psychol. 5 (2), 677-695.

Underwood, B.J., 1975. Individual differences as a crucible in theory construction. Am. Psychol. 30, 128-134.

von Helmholtz, H., 1860/1962. In: Southall, J.P.C. (Ed.), Handbuch der physiologischen optik, vol. 3. Dover Original work published in 1860; Dover English edition in 1962.

Van Berkum, J.J.A., Brown, C.M., Zwitserlood, P., Kooijman, V., Hagoort, P., 2005. Anticipating upcoming words in discourse: evidence from ERPs and reading times. J. Exp. Psychol.: Learn. Mem. Cogn. 31, 443-467.

Van Den Brink, D., Brown, C., Hagoort, P., 2001.

Electrophysiological evidence for early contextual influences during spoken-word recognition: N200 versus N400 effects. J. Cogn. Neurosci. 13 (7), 967-985.

Van Der Elst, W., Van Boxtel, M.P., Van Breukelen, G.J., Jolles, J., 2006. Normative data for the animal, profession and letter $M$ naming verbal fluency tests for Dutch speaking participants and the effects of age, education, and sex. J. Int. Neuropsychol. Soc. 12 (01), 80-89.

Vogel, E.K., Awh, E., 2008. How to exploit diversity for scientific gain: using individual differences to constrain cognitive theory. Curr. Dir. Psychol. Sci. 17 (2), 171-176.

Von Hofsten, C., 2004. An action perspective on motor development. Trends Cogn. Sci. 8, 266-272.

Wassenburg, S.I., Zwaan, R.A., 2010. Readers routinely represent implied object rotation: the role of visual experience. Q. J. Exp. Psychol. 63 (9), 1665-1670.

Watkins, K.E., Strafella, A.P., Paus, T., 2003. Seeing and hearing speech excites the motor system involved in speech production. Neuropsychologia 41 (8), 989-994.

Weber, A., Grice, M., Crocker, M., 2006. The role of prosody in the interpretation of structural ambiguities: a study of anticipatory eye movements. Cognition 99 (2), B63-B72.

Wicha, N.Y.Y., Moreno, E.M., Kutas, M., 2004. Anticipating words and their gender: an event-related brain potential study of semantic integration, gender expectancy, and gender agreement in Spanish sentence reading. J. Cogn. Neurosci. 16, 1272-1288.

Willits, J., Seidenberg, M., \& Saffran, J. 2009. Verbs are looking good in language acquisition. In: Proceedings of the 31st Annual Conference of the Cognitive Science Society, pp. 2570-2575.

Wilson, M., Wilson, T.P., 2005. An oscillator model of the timing of turn-taking. Psychon. Bull. Rev. 12, 957-968.

Wlotko, E.W., Federmeier, K.D., 2007. Finding the right word: hemispheric asymmetries in the use of sentence context information. Neuropsychologia 45 (13), 3001-3014.

Wlotko, E.W., Federmeier, K.D., 2012. Age-related changes in the impact of contextual strength on multiple aspects of sentence comprehension. Psychophysiology 49, 770-785.

Wlotko, E.W., Federmeier, K.D., 2013. Two sides of meaning: the scalp-recorded N400 reflects distinct contributions from the cerebral hemispheres. Front. Psychol. 4, 181.

Wolpert, D.M., Doya, K., Kawato, M., 2003. A unifying computational framework for motor control and social interaction. Philos. Trans. R. Soc.: Biol. Sci. 358, 593-602.

Zwaan, R.A., 2004. The immersed experiencer: toward an embodied theory of language comprehension. Psychol. Learn. Motiv. 44, 35-62.

Zwaan, R.A., 2014. Embodiment and language comprehension: reframing the discussion. Trends Cogn. Sci. 18 (5), 229-234. 